\title{
Lung epithelial CYP1 activity regulates aryl hydrocarbon receptor dependent allergic airway inflammation
}

Running title: Epithelial AhR-CYP1 prevents lung inflammation

Francesca Alessandrini, $\mathrm{PhD}^{1 *}$, Renske de Jong, $\mathrm{PhD}^{1 *}$, Maria Wimmer, $\mathrm{PhD}^{1}$, Ann-Marie Maier, Msc ${ }^{1}$, Isis Fernandez, $\mathrm{PhD}^{2}, 3,4$, Miriam Hils, $\mathrm{PhD}^{5}$, Jeroen T. Buters, $\mathrm{PhD}^{1}$, Tilo Biedermann, $\mathrm{PhD}^{5,6}$, Ulrich Zissler, $\mathrm{PhD}^{1,2}$, Christian Hoffmann, $\mathrm{PhD}^{1,7}$, Julia Esser-vonBieren, $\mathrm{PhD}^{1}$, Carsten B. Schmidt-Weber, $\mathrm{PhD}^{1,2}$, Caspar Ohnmacht, $\mathrm{PhD}^{1}$.

${ }^{1}$ Center of Allergy and Environment (ZAUM), Technical University and Helmholtz Center Munich, Munich, Germany

${ }^{2}$ Member of the German Center of Lung Research (DZL), Munich, Germany

${ }^{3}$ Department of Internal Medicine V, Ludwig-Maximilians-University of Munich (LMU), Munich, Germany.

${ }^{4}$ Comprehensive Pneumology Centre, and Helmholtz Center Munich, Munich, Germany

${ }^{5}$ Department of Dermatology and Allergology Biederstein, School of Medicine, Technical University of Munich, Munich, Germany

${ }^{6}$ Clinical Unit Allergology, Helmholtz Center Munich, Germany

${ }^{7}$ Food Research Center (FoRC), Department of Food Science and Experimental Nutrition, School of Pharmaceutical Sciences, University of São Paulo, São Paulo, Brazil.

*contributed equally

\section{Correspondence}

Caspar Ohnmacht, Center of Allergy and Environment (ZAUM), Technical University and Helmholtz Center Munich, building 57, room 105, Ingolstaedter Landstrasse 1, D-85764 Neuherberg, Germany

email: caspar.ohnmacht@helmholtz-muenchen.de

phone: +498931872556

\section{Conflict of interest}

The authors declare no conflict of interest related to this publication. 


\section{Abstract}

2 The lung epithelial barrier serves as a guardian towards environmental insults and responds to

3 allergen encounter with a cascade of immune reactions that can possibly lead to inflammation.

4 Whether the environmental sensor aryl hydrocarbon receptor (AhR) together with its

5 downstream targets cytochrome P450 (CYP1) family members contribute to the regulation of

6 allergic airway inflammation remains unexplored. By employing knockout mice for AhR and

7 for single CYP1 family members, we found that $\mathrm{AhR}^{-/-}$and CYP1B1 $1^{-/-}$but not CYP1A1 $1^{-/-}$or

$8 \mathrm{CYP}_{\mathrm{A}} 2^{-/-}$animals display enhanced allergic airway inflammation compared to WT.

9 Expression analysis, immunofluorescence staining of murine and human lung sections and bone

10 marrow chimeras suggest an important role of CYP1B1 in non-hematopoietic lung epithelial

11 cells to prevent exacerbation of allergic airway inflammation. Transcriptional analysis of

12 murine and human lung epithelial cells indicates a functional link of AhR to barrier 13 protection/inflammatory mediator signaling upon allergen challenge. In contrast, CYP1B1

14 deficiency leads to enhanced expression and activity of CYP1A1 in lung epithelial cells and to an increased availability of the AhR ligand kynurenic acid following allergen challenge. Thus, differential CYP1 family member expression and signaling via the AhR in epithelial cells represents an immunoregulatory layer protecting the lung from exacerbation of allergic airway 18 inflammation.

Abstract Word Count: 200

Keywords: aryl hydrocarbon receptor, cytochrome P450 enzyme, CYP1B1, eosinophilia, airway epithelial cells 


\section{Introduction}

The aryl hydrocarbon receptor $(\mathrm{AhR})$ is a ligand-activated transcription factor used by immune cells and non-hematopoietic cells to sense the environment and adapt to physiological processes particularly at and within barrier sites such as the skin, the gut or the lung ${ }^{1}$. Upon ligand binding, cytoplasmic AhR translocates to the nucleus to regulate gene transcription either alone or in a complex with other transcription factors. The AhR thereby acts as an intracellular sensor, which is able to respond to a variety of organic compounds including xenobiotics and tryptophane metabolites both from the host and from microbial/ dietary sources. Interestingly, knockout of the AhR or deprivation of AhR ligands has been shown to alter the proper function of the immune system, particularly intestinal type 3 immunity including Th17 cells, innate lymphoid cells type (ILC) 3 and a subset of intraepithelial cells $\mathrm{s}^{2-5}$.

In the context of allergic diseases, ablation of the AhR has been shown to increase the severity of allergic inflammation, indicating a rather protective role of the AhR in these settings ${ }^{6-11}$. In fact, the AhR agonist Tranilast has been successfully employed as anti-allergic drug ${ }^{12-14}$. Noteworthy, the AhR also regulates ILC2 activity $^{15}$, immunogenicity of dendritic cells ${ }^{16}$, macrophage polarization towards a M2 phenotype via mesenchymal cells ${ }^{17}$ and class-switch recombination as well as IL-10 expression in B cells ${ }^{18,19}$. Mechanistically, activation of the AhR typically results in upregulation of the cytochrome P450 (CYP1) members cyp 1a1, cyp 1a2 and cyp $1 b 1^{1}$. CYP enzymes are monooxygenases that catalyze various reactions involved in drug metabolism, synthesis of cholesterol, steroids and other lipids. Importantly, a polymorphism in the CYP1B1 gene has been linked to enhanced risk of bronchial asthma ${ }^{20}$. However, whether and how AhR activity and particularly individual cytochrome P450 members play a role in allergic airway inflammation (AAI) has not been addressed so far.

Therefore, we investigated whether knockout of AhR and individual CYP1 family members differentially impact AAI in murine model systems using clinically-relevant, naturally occurring aeroallergens. We show that AhR and CYP1B1 but not CYP1A1 or CYP1A2 deficiency leads to disease exacerbation in preclinical models of AAI. We further show that airway epithelial cells (ECs) express high levels of CYP1B1 and CY1B1 expression in nonhematopoietic cells is required for protection from exacerbated AAI. AhR deficiency results in alteration of gene expression profiles in primary airway ECs at steady state and even more following AAI, but CYP1B1 deficiency did not. We identified enhanced CYP1A1 activity in $\mathrm{CYP}_{\mathrm{B}} 1^{-/}$ECs and altered tryptophane (Trp) metabolite levels as a possible mechanism responsible for the AAI-potentiating effects observed in CYP1B1 ${ }^{-/-}$animals. This work reveals 
a novel protective role of AhR signaling in airway ECs, which may have the potential to serve as a novel target for therapy of allergic asthma.

\section{Results}

\section{AhR and CYP1B1 deficiency aggravates ragweed-induced allergic airway inflammation}

To assess the role of AhR signaling and cytochrome P450 enzymes in AAI, we sensitized AhR/-, CYP1A1 ${ }^{-/}, \mathrm{CYP}_{1 \mathrm{~A}} 2^{-/-}$and CYP1B1/-- mice to ragweed extract as depicted in Fig 1a. Although the overall detection of serum immunoglobulins was very modest, CYP1B1 $1^{-/}$animals showed a significant increase at the endpoint in total IgE compared to WT (Fig 1b; left panel) and Amb a 1-specific IgG1 level compared to PBS, WT and CYP1A2 ${ }^{-/-}$(Fig 1b; right panel). A tendency towards increased IgE and Amb a 1-specific IgG1 levels was observed also for $\mathrm{AhR}^{-/}$mice albeit not reaching significance (Fig 1b). Enhanced BAL cell infiltration could be observed in $\mathrm{AhR}^{-/-}$and CYP1B1 $1^{-/}$compared to PBS and WT but not to $\mathrm{CYP} 1 \mathrm{~A} 1^{-/-}$and CYP1A2-/- animals (Fig 1c). Differential cell counts revealed that this effect was predominantly due to enhanced infiltration of eosinophils, lymphocytes and macrophages into the bronchoalveolar space (Fig 1c). Additionally, CYP1B1 $1^{-/}$animals revealed enhanced frequencies of Gata $3^{+}$Foxp $^{-}$T helper (Th2) cells in lung tissue compared to PBS, WT, $\mathrm{AhR}^{-/-}$ and CYP1A1/- (Fig 1d). Gene expression analysis of key Th1/Th2-associated cytokines and CCL11 in lung tissue revealed a tendency for increased IL-4 expression in $\mathrm{AhR}^{-/-}$and CYP1B1/. animals, but overall, no significant differences were detected between the investigated genotypes (Fig 1e). Histological analysis of lung tissue showed strongest inflammatory infiltration and mucus hypersecretion in $\mathrm{AhR}^{-/-}$- and CYP1B1 $1^{-/}$animals, although significantly only compared to PBS and not to WT or to other genotypes (Fig 1f). Altogether, these results demonstrate that $\mathrm{AhR}^{-/-}$and $\mathrm{CYP} 1 \mathrm{~B}^{-/-}$animals suffer from a stronger AAI upon chronic exposure to ragweed extract compared to WT and to the other investigated genotypes.

\section{AhR and CYP1B1 deficiency aggravates house dust mite-induced allergic airway} inflammation

In order to assess the allergen specificity of our finding in the ragweed model, we next exposed WT, $\mathrm{AhR}^{-/-}$and CYP1B1 $1^{-/}$animals to HDM-induced AAI (Fig 2a). Here, a more pronounced increase of total serum IgE and a significant increase of Der f specific IgG1 was found both in $\mathrm{AhR}^{-/}$and $\mathrm{CYP} 1 \mathrm{~B} 1^{-/-}$compared to WT mice (Fig 2b, 2g). Further, we found enhanced lung cellular infiltration in the BALF of $\mathrm{AhR}^{-/-}$and $\mathrm{CYP} 1 \mathrm{~B}^{-/-}$animals predominantly due to eosinophils and lymphocytes and macrophages (Fig 2c, 2h). No difference in BALF neutrophils 
was detected (data not shown). In contrast, increased frequencies of Th2 cells could be observed in lung tissue of both genotypes compared to WT (Fig 2d, 2i). AhR ${ }^{-/-}$mice showed three- to fourfold higher levels of IL-4 and IL-13 as well as of CCL11 in lung tissue and a slight increase of IL-17a, whereas CYP1B1 $1^{-/}$mice showed only slightly elevated expression of IL-4, a strong increase of IL-17a and no variations in CCL11 and IL-13 compared to WT (Fig. 2e and 2j). IFN- $\gamma$ levels were not affected in either genotype (data not shown). Lastly, histological analysis of HDM-exposed lungs revealed enhanced peribronchiolar and perivascular infiltration and mucus hypersecretion in both $\mathrm{AhR}^{-/}$and CYP1B1 $1^{-/}$animals compared to WT (Fig $2 \mathrm{f}$ and $2 \mathrm{k}$ ). Altogether our in vivo data from two different adjuvant-free AAI models indicate that both AhR and its downstream target CYP1B1 are essential to prevent excessive AAI in a non-allergenspecific manner.

\section{CYP1B1 is primarily expressed in airway epithelial cells}

Given the selective effect of CYP1B1 expression on the allergic inflammatory response, we then aimed to identify the cell type(s) that primarily express CYP1B1 in the lung and to evaluate if our results can be translated to human. Therefore, we first separated hematopoietic $\left(\mathrm{CD} 45^{+}\right)$ and non-hematopoietic (CD45 cells) from the lungs of naïve $\mathrm{WT}, \mathrm{AhR}^{-/-}$and $\mathrm{CYP} 1 \mathrm{~B} 1^{-/-}$ animals. Strikingly, non-hematopoietic WT lung cells expressed roughly 100-200 times higher levels of CYP1B1 compared to hematopoietic cells at baseline (Fig 3a). Interestingly, CYP1B1 expression was not affected by the absence of AhR (Fig 3a). Immunofluorescence staining of murine lung tissue showed that CYP1B1 stained within bronchial epithelial cells (EC), similarly in control and allergic animals (Fig 3b). Also, in human lung sections, CYP1B1 stained bronchial ECs (Fig 3c). In contrast, CYP1B1 did not stain alveolar ECs in mouse or human lung sections (Fig 3b, c). These data are in line with single cell expression data demonstrating CYP1B1 but not CYP1A1 or CYP1A2 expression across different subsets of human lung epithelial and fibroblastic cells (Supplementary Fig S1).

To assess whether human lung ECs are directly regulated by AhR signaling, normal human bronchial epithelial cells (NHBE) were stimulated for $24 \mathrm{~h}$ with HDM in the presence of IL-4 (to mimic an 'allergic' status), an AhR inhibitor or the combination of both. As expected, microarray analysis revealed a strong effect of HDM exposure compared to non-exposed cells (not shown). Whereas IL-4 strongly stimulated the expression of typical pro-allergic genes such as CCL26 or IL13R2 and interestingly also $A H R$ (Fig 3d and Supplementary Table S3), AhR inhibition led to a more drastic change in differentially expressed genes (DEGs) compared to IL-4 (Supplementary Table S3). We then focused the analysis on the DEGs mostly altered 
130 solely by the inhibition of AhR during HDM exposure. As expected, inhibition of AhR led to downregulation of the AhR target genes CYP1A1 and CYP1B1 irrespective of whether IL-4 was present or not. Noteworthy, the inhibition of AhR lead to a strong upregulation of genes critical

133 for allergic tissue inflammation, e.g. cell recruitment (CX3CL1), barrier integrity/protection 134 (ITGB3, PIGR), antigen presentation (HLA-DRA, HLA-DMB), Th2 differentiation (IL19) and 135 lipid mediator synthesis (ALOX15) (Fig 3d and Supplementary Table S3).

136 Thus, bronchial ECs seem to be the major CYP1B1-expressing cell type in murine and human 137 lung. Furthermore, AhR activity in allergen-exposed NHBEs regulates a number of genes associated to AAI.

Non-hematopoietic expression of CYP1B1 protects from exacerbation of HDM-induced allergic airway inflammation

142 Given the predominant expression of CYP1B1 in mouse and human bronchial ECs, we then

143 investigated whether non-hematopoietic expression of CYP1B1 is sufficient to prevent exacerbation of AAI. To this end, we generated CYP1B1/-- and WT bone marrow chimeras (Fig 4a) and sensitized them to HDM, as depicted in Fig. 2a. Strikingly, only CYP1B1 ${ }^{-/-}$chimeras with WT hematopoietic cells mirrored previously detected parameters of elevated AAI in full $\mathrm{CYP}_{\mathrm{B}} 1^{-/-}$mice, including serum immunoglobulin response (Fig 4b), BAL total cell numbers, particularly eosinophils and lymphocytes (Fig 4c), lung-resident Th2 cells (Fig 4d), IL-4 and IL-17 in BALF (Fig 4e) and histological scores in lung sections (Fig 4f). Conversely, WT chimeras with $\mathrm{CYP} 1 \mathrm{~B} 1^{-/}$hematopoietic cells showed much milder symptoms of AAI. Thus, CYP1B1 expression in non-hematopoietic cells is primarily responsible to prevent exaggerated AAI after exposure to HDM.

Transcriptional comparison indicates AhR- but not CYP1B1-dependent regulation of bronchial epithelial cells

156 To get a deeper insight into the molecular mechanism responsible for AhR- and CYP1B1157 dependent effects, we performed RNA sequencing of sort-purified primary lung ECs $158\left(\mathrm{CD}^{-} 5^{-} \mathrm{CD} 31^{-} \mathrm{EpCAM}^{+} \mathrm{live}^{+}\right)$at steady state and after HDM-elicited-AAI. The analysis of the number of DEGs in $\mathrm{AhR}^{-/-}$and $\mathrm{CYP} 1 \mathrm{~B} 1^{-/-}$relatively to WT showed a stronger impact of the deficiency of AhR compared to CYP1B1 in gene regulation, especially following HDM exposure (Fig 5a). In fact, at steady state, we detected only few DEGs between WT and AhRdeficient ECs. Interestingly, some of these genes have been linked to regulation of circadian clock (Nrld1, Nrld2, Cryl) (Fig 5b). Following HDM-induced allergy, ECs from AhR ${ }^{-/-}$ 
164 showed a strongly altered gene expression profile, contrarily to CYP1B1 $1^{-/}$, which showed only 165 low DEGs compared to WT with and none without allergy (Fig 5b and Supplementary Table S4). KEGG pathway analysis revealed an overall upregulation of genes involved in cell-to-cell contact and TGF- $\beta$ signaling whereas genes associated to pattern recognition (TLR-like and NOD-like receptor signaling), chemokine receptor signaling and JAK-STAT signaling pathway were overall downregulated (Fig 5c and Supplementary Table S5). Overall, these data indicate that $\mathrm{AhR}$, but not CYP1B1, is a major transcriptional regulator of ECs function, particularly after exposure to aeroallergens.

Absence of CYP1B1 leads to enhanced transcription and activity of CYP1A1 and to altered tryptophane metabolites levels

175 Our results indicating a non-transcriptional effect of CYP1B1 deficiency in ECs prompted us 176 to investigate underlying mechanisms responsible for the enhanced allergic phenotype in $177 \mathrm{CYP}_{\mathrm{BB}} 1^{--}$mice. Since artificial overexpression of CYP1A1 is known to limit availability of AhR agonists in vivo ${ }^{5}$, we measured the expression of CYP1A1 in the absence of CYP1B1. Interestingly, lung tissue of CYP1B1/- animals showed higher CYP1A1 expression levels compared to WT both at steady state and in tendency also following RWE-induced AAI, whereas CYP1A1 was not detected in $\mathrm{AhR}^{-/-}$or CYP1A1 $1^{-/-}$lung tissue (Fig 6a, b). Similarly, higher CYP1A1 expression compared to WT could be observed in CYP1B1 ${ }^{-/}$lung tissue following HDM-induced AAI (Fig 6c). Notably, this effect was even more pronounced in purified non-hematopoietic $\left(\mathrm{CD} 45^{-}\right)$cells from HDM-allergic lungs with a roughly 20-fold higher CYP1A1 expression in the absence of CYP1B1 (Fig. 6d).

To assess whether the HDM extract used for sensitization directly activates the AhR in ECs, we stimulated lung homogenates from all investigated genotypes with HDM extract or with the prototypical AhR ligand FICZ and compared the resulting EROD activity. HDM induced a slight, yet non-significant increase of EROD activity only in CYP1B1 ${ }^{-/-}$animals compared to WT (Fig 6e). In contrast, FICZ induced EROD activity indistinctively in WT and CYP1B1-/but not in all other genotypes (Fig 6f). As CYP1B1 was predominantly expressed in ECs (Fig 3), we measured EROD activity in primary murine tracheobronchial ECs (MTECs). Here, HDM did not elicit EROD activity in any background, whereas FICZ induced highest EROD activity in CYP1B1 ${ }^{-/}$compared to WT, but not in $\mathrm{AhR}^{-/-}$MTECs (Fig 6g). As expected, baseline CYP1A1 expression was higher in CYP1B1 $1^{-/}$MTEC cultures compared to WT and

196 further increased following FICZ stimulation (Fig 6h). Since the HDM extract used for 197 sensitization lacked AhR activation properties, we investigated whether endogenously 
produced AhR ligands would be affected by a disrupted AhR-CYP1 axis. Therefore, the endogenous AhR ligands of the Trp pathway kynurenine (Kyn) and kynurenine acid (KynA) ${ }^{21 \text {, }}$ ${ }^{22}$ were measured in lung homogenates at steady state and following AAI. Interestingly, Kyn levels increased in WT and CYP1B1 $1^{-/}$lung cells after AAI while this did not reach significance for $\mathrm{AhR}^{-/-}$(Fig 6i). In contrast, KynA levels decreased after AAI in lungs of WT mice, but not in $\mathrm{AhR}^{-/-}$nor in CYP1B1 $1^{-/}$lungs (Fig 6i). In summary, these results point towards a crossregulation of different CYP1 family members in bronchial ECs and to the employment of selective endogenous AhR ligands in regulating AhR activity in lung tissue following HDMinduced AAI.

\section{Discussion}

Here, we provide evidence of an important role of the AhR-CYP1 axes in preventing exacerbation of AAI using two adjuvant-free murine models with clinically-relevant aeroallergens. In fact, ablation of the $\mathrm{AhR}$ as well as of the immediate AhR response-gene CYP1B1 resulted both in enhanced AAI upon exposure to both RWE and HDM, as characterized by serum immunoglobulins, lung inflammatory cell infiltration and mucus hypersecretion. Our results confirm a recent study showing enhanced AAI and remodeling in an ovalbumin-induced chronic asthma model using $\mathrm{AhR}^{-/-}$compared to WT mice ${ }^{10}$ and complete the picture adding the role of the CYP1 gene family. Whether a similar mechanism is present in humans remains to be elucidated. Still, CYP1B1 expression was clearly confined to bronchial and bronchiolar ECs in mouse and human, in line with early reports showing upregulation of CYP1B1 expression upon exposure to AhR ligands within club cells of peripheral airways ${ }^{23,24}$. Besides the well-known upregulation of CYP1B1 in an AhR-dependent manner, we also found basal CYP1B1 expression independent of AhR (Fig. 3a) which has also been reported earlier in different settings ${ }^{25}$, 26. Thus, we suggest that CYP1B1 is most likely active in steady state conditions but inflammation may potentiate CYP1B1 (and CYP1A1) expression and activity in an AhR-dependent manner.

225 Functionally, we demonstrate that a well-balanced AhR-CYP1 activity in non-hematopoietic 226 cells is decisive in the protection from disease exacerbation, as only $\mathrm{CYP} 1 \mathrm{~B} 1^{-/-}$chimeras with WT hematopoietic cells reproduced the previously detected parameters of elevated AAI in full $\mathrm{CYP}_{\mathrm{B} 1}{ }^{-/}$mice. As opposed to CYP1B1, we did not observe any consistent effect of CYP1A1 nor CYP1A2 deficiency in AAI, conforming to their low expression in bronchial ECs (Fig S1). Noteworthy, previous studies have already suggested a protective role of AhR in skin and intestinal inflammatory disorders $6,8,27$. Interestingly, immune regulation in the skin has been 
associated to AhR activity in non-hematopoietic cells, presumably keratinocytes ${ }^{6}$, confirming the critical role of AhR in epithelium as an interface between environment and mucosal

234 immunity.

235 What is the consequence of the paucity of AhR signaling in lung epithelial cells?

236 Our transcriptional analysis of primary lung epithelial cells from non-allergic mice revealed 237 only relatively few differentially expressed genes in the absence of AhR signaling and almost 238 none in the absence of CYP1B1. Surprisingly, the majority of these AhR-dependent genes 239 indicates a deregulation of the peripheral circadian clock. Interestingly, some key effector cells 240 in allergy, such as mast cells, show circadian regulation patterns ${ }^{28}$ and ablation of circadian 241 clock genes in lung ECs has been shown to aggravate inflammation ${ }^{29,30}$. Whether disruption of 242 peripheral circadian clock networks has a functional impact in our model should be matter of 243 future investigations. In contrast to the relatively few DEGs found in airway ECs from $\mathrm{AhR}^{-/-}$ 244 mice at steady-state, we identified strong differences in gene expression of airway ECs from $245 \mathrm{AhR}^{-/-}$but not CYP1B1 ${ }^{-/-}$animals following HDM exposure. Pathway analysis of these DEGs revealed a role for AhR to ensure epithelial barrier function, limit TGF- $\beta$ receptor signaling and 247 regulate a number of pathways associated to pattern recognition receptor or cytokine/chemokine signaling ${ }^{31,32}$. Some of these pathways may not be regulated directly by the AhR, but are rather a consequence of the enhanced $\mathrm{AAI}$ observed in $\mathrm{AhR}^{-/-}$mice. On the other hand, the lack of DEGs in ECs from healthy and allergic CYP1B1 ${ }^{-/-}$animals, despite the enhanced AAI similar to $\mathrm{AhR}^{-/-}$, suggests that CYP1B1 deficiency in airway ECs affects hematopoietic cell types by other means. To investigate the mechanism responsible for the key role of CYP1B1 in airway ECs, we first assessed the expression of CYP1A1 in the absence of CYP1B1. As our results indicate enhanced activity of CYP1A1 in lung epithelial cells in the absence of CYP1B1, they point towards a cross regulation of CYP1 family members in lung ECs. This finding is in line with earlier studies showing that lungs and livers of CYP1B $1^{-/-}$ animals stimulated with carcinogenic agents had elevated levels of CYP1A1 expression ${ }^{33,34}$. As aeroallergens typically interact with the epithelium as particles containing multiple molecules, we also tested whether HDM extracts were able to activate the AhR pathway directly, but did not find functionally relevant quantities of AhR ligands in HDM extracts able to activate WT cells. This suggests that naturally occurring activating ligands of AhR, e.g. of 262 the Trp pathway ${ }^{35,36}$, may be sufficient for AhR-dependent regulation of AAI. To test this 263 hypothesis, we conducted a targeted metabolomics approach to quantify key endogenous AhR 264 ligands of the Trp pathway in lung tissue of WT compared to AhR-and CYP1B1-deficient mice at steady state and following HDM-driven AAI. Interestingly, in WT and CYP1B1 ${ }^{-/}$lungs, but 
not in $\mathrm{AhR}^{-/}$, levels of the AhR ligand Kyn increased after AAI. As AhR expression in lung ECs is directly induced by IL-4 signaling (Supplementary Table S3 and ${ }^{37,38}$ ), enhanced AhR activity during AAI, fueled with endogenous ligands, may serve as a feedback loop to protect airway ECs from excessive inflammation ${ }^{16,39}$.

Moreover, contrarily to Kyn, the levels of the acid form KynA decreased in WT after AAI. A plausible explanation for this observation could be the preferential use of KynA for AhRdependent regulation of AAI in vivo, as KynA has a higher affinity to AhR compared to Kyn ${ }^{21}$. Interestingly, KynA levels remained high in lungs of CYP1B1 $1^{-/}$and $\mathrm{AhR}^{-/-}$mice after AAI. In our study we focused on the two most relevant AhR ligands but further studies should assess the role of additional host-intrinsic AhR ligands. Degradation of AhR ligands by excessive CYP1A1 activity has already been identified previously as an important feedback mechanism to negatively regulate activity and duration of AhR signaling and can therefore functionally mimic AhR deficiency in the intestinal tract ${ }^{5}$. Thus, enhanced CYP1A1 activity in the absence of CYP1B1 may explain a comparable defect of immune regulation in $\mathrm{AhR}^{-/-}$and $\mathrm{CYP} 1 \mathrm{~B} 1^{-/-}$ animals upon repetitive contact with aeroallergens. Indeed, the activity of individual CYP1 members are able to differentially modulate the availability of local AhR ligands thereby regulating AhR activity in hematopoietic cells such as ILC2s or macrophages, known players in AAI expressing $\mathrm{AhR}^{15}$, in analogy to a similar scenario recently proposed for intestinal ECs and skin keratinocytes ${ }^{5,40}$.

In summary, this work extends a role of the AhR in the regulation of lung non-hematopoietic cells. Moreover, it suggests that balanced AhR/CYP1 activity within ECs represents an important layer of immune regulation necessary to prevent exacerbation of allergic responses in the lung and offers novel possibilities for tailor-made strategies in immune regulation at barrier sites.

\section{Methods}

\section{Mice and human samples}

293 The following genotypes were used: C57BL/6 wildtype (WT), and $\mathrm{AhR}^{-/-41}, \mathrm{CYP}_{\mathrm{A}} 1^{-/-42}$, 294 CYP1A2 $2^{-/ 43}$ and CYP1B1 $1^{-/ 33}$, all backcrossed to C57BL/6. All mice were bred and kept under specific pathogen-free conditions in individually ventilated cages at the central animal facility of Helmholtz Center Munich. Mice were kept in autoclaved, individually ventilated cages (501 $\mathrm{cm}^{2}$, IVCs) with stocking density according to the EU guideline 2010/63 with a 12 hour dark/light cycle. Each cage was supplied with autoclaved bedding, bite sticks, nestles and 
water were provided ad libitum. Cage manipulation took place in laminar flow hoods. Air temperature was $22 \pm 2^{\circ} \mathrm{C}$ and humidity $55 \pm 10 \%$ with daily control and record. Occasionally, C57BL/6 wildtype animals were bought from Charles River (Sulzfeld, Germany). In this case, mice were allowed to acclimatize for at least one week before sensitization. Both male and female mice over the age of 7 weeks were used. For the generation of bone marrow chimeras, recipient mice were lethally irradiated by a Co60 source with two doses of 6 Gray $4 \mathrm{~h}$ apart. Irradiated mice were reconstituted with $8 \times 10^{6}$ purified bone marrow cells of respective donors by i.v. injection. After reconstitution, mice received $0.25 \mathrm{mg} / \mathrm{ml}$ Enrofloxacin (Baytril; Bayer Vital $\mathrm{GmbH}$ ) in drinking water for 3 weeks. Mice were maintained for 10-12 weeks to allow replacement of the hematopoietic system before allergen sensitization protocols were applied.

311 Experiments were performed on age- and sex-matched animals kept in the same rack, according

312 to the European Convention for Animal Care and Use of Laboratory Animals and were 313 approved by local ethics committee and government authorities (ROB-55-2-2532.Vet_02-1831494 and 55.2-1-54-2532-156-12). Human samples were obtained from the BioArchive of the 315 Comprehensive Pneumology Center Munich. All patients gave written informed consent and 316 the study was approved by local ethics committee of the Ludwig-Maximilians University of 317 Munich, Germany number 19-630).

\section{Preparation of ragweed and house dust mite extracts}

320 Aqueous ragweed pollen extracts (RWE) were prepared as previously described ${ }^{44}$. Briefly, 321 ragweed pollen were suspended in PBS $(2.5 \mathrm{mg} / \mathrm{ml})$, incubated for $30 \mathrm{~min}$ at $37^{\circ} \mathrm{C}$ and then centrifuged for $10 \mathrm{~min}$ at $4000 \mathrm{rpm}$ by $4^{\circ} \mathrm{C}$. The supernatants were sterile filtered through a $0.22 \mu \mathrm{m}$ syringe filter (Merck KGaA, Darmstadt, Germany) and frozen at $-80^{\circ} \mathrm{C}$. House dust mite extracts from Dermatophagoides farinae (Stallergene Greer Laboratories, Kamp-Lintfort, Germany and Citeq BV, Groningen, NL) were suspended in $9 \% \mathrm{NaCl}(1 \mathrm{mg} / \mathrm{ml})$ and stored at $-20^{\circ} \mathrm{C}$ until use. The final solution for intranasal instillation was prepared in PBS.

\section{Mouse models of allergic airway inflammation}

329 For the ragweed model, a sensitization protocol previously established in BALB/c mice ${ }^{44}$ was 330 adapted to C57BL/6. In short, mice received bilateral intranasal (i.n.) instillations of ragweed pollen extract (RWE) $(20 \mathrm{mg} / \mathrm{ml} ; 10 \mu \mathrm{l} /$ nostril) once a day for a total of 23 days in 5 consecutive weeks. For the HDM model, mice were sensitized once by bilateral i.n. instillations of house 
334 Greer Laboratories, Kamp-Lintfort, Germany and Citeq BV, Groningen, NL). After eight days, mice were challenged with $\operatorname{HDM}(500 \mu \mathrm{g} / \mathrm{ml} ; 10 \mu \mathrm{l} /$ nostril $)$ for 4 consecutive days. Control animals of both protocols received same amounts of PBS. Weight was monitored throughout the whole experiment. Mice were sacrificed either 24 or $72 \mathrm{~h}$ after the last instillation for the RWE or HDM protocol, respectively. After recovery of serum and bronchoalveolar lavage fluid $(\mathrm{BALF})^{44}$, lung tissue was prepared for histology, immunofluorescence, real-time PCR or FACS analysis. Non-lavaged lungs were used for characterization of non-hematopoietic cells by immunomagnetic- or flow cytometry-based cell separation, real-time PCR and metabolite analysis.

\section{Analysis of plasma immunoglobulins}

345 Plasma samples were prepared from blood taken prior to sensitization (day 0 ) and at sacrifice

346 (endpoint). Total IgE and RWE-specific IgG1 were measured as previously described ${ }^{44}$. For 347 the detection of Dermatophagoides farinae (Der-f)-specific IgG1, 96-well plated were coated 348 with goat anti-mouse IgG1 (CITEQ Biologics, Groningen, Netherlands) and mouse plasma was added. Subsequently, samples were incubated with biotinylated Der-f (CITEQ), avidinhorseradish peroxidase (Biolegend, San Diego, CA, USA), tetramethylbenzidine (ThermoFisher Scientific, Rockford, IL, USA) and read at $450 \mathrm{~nm}$ according to the manufacturer's instructions.

\section{Analysis of bronchoalveolar lavage (BAL) and lung histology}

355 BAL and evaluation of inflammatory cell infiltration were performed as described previously ${ }^{44}$. Aliquots of cell-free BAL fluid were used to measure cytokines using a Multiplex-bead-array (Mouse ProcartaPlex, Thermo Fisher Scientific, Waltham, MA, USA) according to manufacturer's instructions. For lung histology, after BAL, the lungs were excised and the left lobe fixed in $4 \%$ buffered formalin and embedded in paraffin. Sections of $4 \mu \mathrm{m}$ thickness were stained with hematoxylin-eosin (H\&E) and periodic acid Schiff (PAS). Mucus hypersecretion and inflammatory cell infiltration were graded in a blinded fashion on a scale from 0 to 4 $(0=$ none, $1=$ mild, $2=$ moderate, $3=$ marked, $4=$ severe $)$, reflecting the degree of the pathological alteration $^{45}$.

\section{Immunofluorescence}

366 Immunofluorescence staining was performed on mouse and human lung tissue embedded in 367 paraffin. Slides were deparaffinized overnight at $60{ }^{\circ} \mathrm{C}$ and rehydrated in a graded series of 
ethanol and distilled water. For antigen retrieval the slides were immersed in citrate buffer solution ( $\mathrm{pH}$ 6.0) and placed into a Decloaking Chamber heated up to $125^{\circ} \mathrm{C}$ (30 seconds), 90 ${ }^{\circ} \mathrm{C}$ (10 seconds), and cooled down to room temperature. Following a washing step in Tris buffer, blocking with 5\% BSA in Tris buffer, the slides were double-stained with CYP1B1 rabbit polyclonal (aa400-450) antibody (LS-B1790, LifeSpan BioSciences, Inc., Seattle, WA, USA) and CC10 mouse monoclonal antibody (E-11) (sc-365992, Santa Cruz Biotechnology, Inc., Dallas, TX, USA). The primary antibodies were diluted in antibody diluent (Zytomed Systems, Berlin, Germany), CYP1B1 (1:50) and CC10 (1:100). For isotype control, rabbit IgG (sc-3888, Santa Cruz Biotechnology, Inc.) and mouse IgG1 kappa isotype control (16-4714-82, Invitrogen, Carlsbad, CA, USA) were used. The staining with the primary antibody occurred overnight in a wet chamber at $4{ }^{\circ} \mathrm{C}$. After rinsing in Tris buffer, a 1:250 dilution of each secondary antibody (Alexa Fluor 488 donkey anti-mouse and Alexa Fluor 568 donkey antirabbit, respectively for CYP1B1 and CC10 antibodies, Thermo Fisher Scientific), as well as DAPI (Sigma-Aldrich; St Louis, MO, USA, 1:2000) was applied to the slides and incubated 1 hour at room temperature in the dark. After rinsing again in Tris buffer, the slides were mounted in Fluorescence Mounting Medium (Dako, Hamburg, Germany). Images of the sections were obtained using Axiovert II (Carl Zeiss) and processed using the ZEN 3.2 software (blue edition, Carl Zeiss).

\section{Flow cytometry of murine lungs}

388 After sacrifice, lungs were perfused with PBS, minced and digested in RPMI 1640 (Gibco, Life 389 Technologies GmbH, Darmstadt, Germany) containing $1 \mathrm{mg} / \mathrm{ml}$ collagenase A (SigmaAldrich) and $100 \mu \mathrm{g} / \mathrm{ml}$ DNase I (Sigma-Aldrich) at $37^{\circ} \mathrm{C}$ for 30 minutes. Digested lungs were meshed and filtered through a 70- $\mu \mathrm{m}$ cell strainer and centrifuged at $500 \times \mathrm{g}$ for $10 \mathrm{~min}$. Cell pellets were resuspended in a 40\% Percoll (GE Healthcare, South Logan, USA) solution and layered onto an $80 \%$ Percoll layer. The Percoll gradient was run at $1500 \times \mathrm{g}$ at room temperature for $15 \mathrm{~min}$. The interlayer containing mononuclear cells was collected, washed and incubated with Fc block (BD) and stained with the corresponding antibodies for 30 minutes on ice. Intracellular staining was performed using a Foxp3 fixation/permeabilization kit (eBiosciences, San Diego, CA, USA) according to the manufacturer's instructions. Live/Dead exclusion was routinely performed using a kit from Life Technologies. Antibodies used for flow cytometry are listed in Supplementary Table S1 and the gating strategy employed for the identification of lung Th2 cells is depicted in Supplementary Fig. S2a. 
402

403

404

405

406

407

408

409

410

411

412

413

414

415

416

417

418

419

420

421

422

423

424

425

426

427

428

429

430

431

432

433

434

\section{Measurement of tryptophane metabolites in lung tissue}

Lungs were excised, weighted, cut into small pieces and snap frozen in liquid nitrogen. All solvents used for metabolite analysis were from Sigma Aldrich, LC-MS grade. For the extraction, a mixture of ice-cold methanol:acetonitrile:water $(3: 2: 1, \mathrm{v} / \mathrm{v}, 600 \mu \mathrm{l})$ was added to 100-150 mg frozen tissue. The tissue was lysed using a tissue Lyser (Qiagen), vortex for $1 \mathrm{~min}$ at $4-8{ }^{\circ} \mathrm{C}$ and incubated for $4 \mathrm{~h}$ at $-20^{\circ} \mathrm{C}$. After 10 minutes centrifugation at $14,000 \mathrm{~g}$ at $4-8{ }^{\circ} \mathrm{C}$, the supernatant was collected. Methanol $80 \%$ (vol/vol, $-20{ }^{\circ} \mathrm{C}, 400 \mu \mathrm{l}$ ) was added to the precipitate, each sample was vortexed for 1 minute at $4-8{ }^{\circ} \mathrm{C}$, and incubated for 30 minutes at $-20^{\circ} \mathrm{C}$. After centrifugation at $14,000 \mathrm{~g}$ for 10 minutes at $4-8{ }^{\circ} \mathrm{C}$, the supernatant was collected and combined to the supernatant of the first extraction step from the same sample. After a final centrifugation step at $14,000 \mathrm{~g}$ for 10 minutes at $4-8^{\circ} \mathrm{C}$, the supernatant was collected and stored at $-80{ }^{\circ} \mathrm{C}$ until LC-MS/MS analysis by targeted metabolomics. Before mass spectrometric analysis, $200 \mu \mathrm{l}$ of the extracts were dried down in a vacuum centrifuge and resolubilized in $100 \mu \mathrm{l}$ of $5 \mathrm{mM}$ ammonium bicarbonate in water. Reversed phase liquid chromatographytandem mass spectrometry (LC-MS/MS) was used for the quantification of metabolites by directly injecting $1 \mathrm{ul}$ of the resolubilized mixture onto an Atlantis PREMIER BEH C18 AX VanGuard FIT Column, (2.5 $\mu \mathrm{m}, 2.1$ x 100 mm; Waters). A RSLC ultimate 3000 (Thermo Fisher Scientific) HPLC system was used, directly coupled to a TSQ Quantiva mass spectrometer (Thermo Fisher Scientific) via electrospray ionization. A 8-minute-long linear gradient was used, beginning with 99\% A (5 mM ammonium bicarbonate in water) linearly rising up to $70 \% \mathrm{~B}(95 \%$ Methanol and 5\% $5 \mathrm{mM}$ ammonium bicarbonate in water) employing a flow rate of $100 \mu \mathrm{l} / \mathrm{min}$. LC-MS/MS was performed by employing the selected reaction monitoring (SRM) mode of the instrument using the transitions (quantifiers) $205.1 \mathrm{~m} / \mathrm{z} \rightarrow 188.1$ $m / z$ (tryptophan); $209.1 \mathrm{~m} / \mathrm{z} \rightarrow 192.1 \mathrm{~m} / \mathrm{z}$ (kynurenine); $190.1 \mathrm{~m} / \mathrm{z} \rightarrow 144.1 \mathrm{~m} / \mathrm{z}$ (kynurenic acid) in the positive ion mode. Authentic metabolite standards (Merck) were used for determining the optimal collision energies for LC-MS/MS and for validating experimental retention times. Ion chromatograms were interpreted manually using Xcalibur (Thermo Fisher Scientific).

\section{Immunomagnetic cell isolation of non-hematopoietic cells from murine lungs}

For the isolation of CD45- and CD45+ cells lungs were flushed with PBS and digested as described above. CD45- cells were separated by negative selection from CD45+ cells using CD45 MicroBeads and LC separation columns (all Miltenyi Biotech GmbH, Bergisch Gladbach, Germany), according to the manufacturer's protocol. After controlling for cell purity 
by flow cytometry, cell pellets were lysed in RNA-lysis buffer (Zymo Research, Freiburg, Germany) and further processed for real-time PCR analysis.

\section{RNA extraction and real-time PCR}

RNA extraction of whole lung pieces or purified cells was performed using the Quick-RNA

Miniprep or Quick-RNA Microprep (Zymo Research), respectively, according to the manufacturer's instructions and RNA was reversed transcribed with a cDNA synthesis kit

442 (Fermentas, Thermo Fisher Scientific). For qPCR, a SYBR green-containing master mix (Roche, Basel, Switzerland) was used. Genes were run in triplicates in a 384 well format using a light cycler (Roche) and normalized to two housekeeping genes. The relative expression was calculated with the $2^{-\Delta \mathrm{CT}}$ method and typically fold change above control or wildtype are shown as indicated. Primer sequences are listed in Supplementary Table S2.

\section{Normal human bronchial epithelial cell (NHBE) cell culture}

NHBE culture was performed as previously described ${ }^{38}$. Briefly, primary NHBEs (Lonza, humidity and $5 \% \mathrm{CO}_{2}$ at $37{ }^{\circ} \mathrm{C}$ in serum-free defined growth media (BEGM, Lonza). NHBEs (passage 3 ) were used at $\sim 80 \%$ confluence in 6 -well plates. To avoid gene expression changes or influences by growth factors in the BEGM medium, cells were rested in basal medium (BEBM, Lonza) for $12 \mathrm{~h}$, then stimulated with HDM extract at a final concentration of $40 \mu \mathrm{g} / \mathrm{mL}$ (CITEQ), recombinant human IL-4 at $50 \mathrm{ng} / \mathrm{ml}$ (R\&D Systems, Minneapolis, MN, USA) for 6 were lysed in RLT buffer (Qiagen, Hilden, Germany) containing 1\% $\beta$-mercaptoethanol (Roth, Karlsruhe, Germany) directly in the cell culture well.

\section{RNA extraction, quantification and microarray analysis of human NHBE}

Total RNA was extracted using RNeasy Mini Kit (Qiagen, Hilden, Germany). RNA quantification and quality assessments were performed by ultraviolet-visible spectrophotometry (Nanodrop Technologies, Wilmington, DE) and the RNA 6000 Nano Chip Kit with the Agilent 2100 Bioanalyzer (Agilent Technologies, Santa Clara, CA, USA). RNA quality of all samples reached a RNA integrity number (Agilent Technologies) of $>8.5$. Total RNA was amplified and Cy3 labeled by using the one-color Low Input Quick Amp Labeling 
SurePrint G3 Human Gene Expression 8x60K Microarrays (Agilent Technologies) was performed with the Gene Expression Hybridization Kit (Agilent Technologies).

\section{Data analysis strategy for microarray}

472 For microarray, data analysis was performed using the Genespring Software GX 14.9.1 (Agilent 473 Technologies) under minimal data reduction constraints (1.5-fold change and $\mathrm{P} \leq 0.05$ cutoff). 474 Upon data import a standard baseline transformation to the median of all values was performed, 475 including $\log$ transformation and computation of fold changes $(\log 2(\mathrm{~A} / \mathrm{B})=\log 2(\mathrm{~A})-\log 2(\mathrm{~B}))$. Subsequently, a principle component analysis was conducted and revealed a homogenous component distribution. Compromised array signals (array spot non uniform due to pixel noise of feature exceeding threshold or above saturation) were excluded from further analysis. Genes regulated more than 1.5-fold were further analyzed by using the paired Student's t-test and filtered for $\mathrm{P}$-value of $<0.05$ ). The significantly regulated genes were summarized in entity lists (see Supplementary Table S3). Only differentially expressed probes annotated with a Gene Symbol were considered for further analysis. Probe intensities were averaged in cases where more than one probe per genes was considered differentially expressed, and the lowest $p$ value among these probes was considered for plotting. Genes annotated as protein coding, using the Bioconductor's AnnotationHub package (Ensemble Human Genome version 99) were used as input for a KEGG map enrichment test as described for RNA-seq data. Microarray data have been deposited in NCBI's Gene Expression Omnibus (GEO) and are accessible through GEO Series accession number XXX (will be annotated after acceptance).

\section{Generation of mouse tracheobronchial epithelial Cells (MTEC) cultures}

491 Mouse tracheobronchial epithelial cells (MTEC) were isolated and differentiated as described previously ${ }^{46}$. Briefly, mouse tracheas were surgically removed and placed in $10 \mathrm{ml} 0.15 \%$ pronase solution (Roche, Basel, $\mathrm{CH}$ ) and incubated overnight at $4{ }^{\circ} \mathrm{C}$. On the second day, a single cell suspension was generated by gently rocking the digested trachea. To remove fibroblasts, a native selection step was performed by incubating the cell suspension at $37^{\circ} \mathrm{C}$ in an atmosphere of $95 \%$ air, $5 \% \mathrm{CO}_{2}$ for $5 \mathrm{~h}$ in MTEC basic medium containing $10 \% \mathrm{FCS}^{46}$. 


\section{EROD-Assay}

503 To determine CYP1A1 enzyme activity an EROD Assay was performed. When indicated, cells 504 were stimulated with HDM or the known AhR agonist FICZ (5,11-Dihydroindolo[3,2505 b]carbazole-6-carboxaldehyde, Tocris Bioscience, Bristol, UK or Sigma-Aldrich) to activate 506 the AhR and induce CYP1A1 transcription. Prior to the start of the assay, cells seeded in round507 bottom cell culture plates (96 well) were washed twice with pre-warmed PBS $\left(37^{\circ} \mathrm{C}\right)$. After 508 aspirating the PBS, the desired volume of EROD reaction mixture [ $5 \mu \mathrm{M}$ Ethoxyresorufin (7509 ER, Sigma-Aldrich), 0.5 mM NADPH (Sigma-Aldrich), 1.0 mg/ml BSA (Sigma-Aldrich), 50 $510 \mathrm{mM}$ Tris ( $\mathrm{pH}$ 7.4)] was pipetted into the plate and subsequently incubated for 20 minutes at 37 $511{ }^{\circ} \mathrm{C}$. To terminate the reaction $2 \mathrm{M}$ glycine (Sigma-Aldrich, $\mathrm{pH} 10.3-10.4$ ) was added in a 1:1.5 512 ratio of glycine:EROD mixture volume. Supernatants were spun down at RT for 1-2 minutes to 513 pellet any cellular debris. Subsequently, a fixed fraction of the supernatant was pipetted into a 514 new plate. The plate was read at 535-550nm excitation and 570-590nm emission with a 515 spectrophotometer (InfiniteM200pro, TECAN).

\section{Isolation of primary mouse alveolar epithelial cells}

518 Mouse primary alveolar epithelial cells were isolated as described previously ${ }^{47}$. Briefly, cardiac perfusion was performed using DPBS (Life Technologies). Subsequently, a cannula was placed in the trachea to infuse, first, dispase $(50 \mathrm{U} / \mathrm{ml}$, Roche) for $\sim 45$ seconds to allow the enzyme to distribute throughout the lungs without allowing it to spill back out. Next, $1 \mathrm{ml}$ of $1 \%$ low-melt agarose (Sigma Aldrich) was gently infused. Lungs were covered with crushed ice for 2 minutes to allow for the agarose to solidify. Individual intact lung lobes were cut away and additionally kept in a dispase solution ( $50 \mathrm{U} / \mathrm{ml}$, Roche) for $45 \mathrm{~min}$ at room temperature on a rocker at 150 rpm. After 45 minutes digested lungs were decanted in complete DMEM/F-12 (Gibco, Life Technologies) with DNase I (Qiagen) for 10 minutes to avoid clumping of cells. Single cell preparations were serially strained though a $100 \mu \mathrm{m}, 70 \mu \mathrm{m}$ and $40 \mu \mathrm{m}$ strainers. Primary epithelial cells (singlets, alive, CD45-, EpCAM+ cells) were isolated with a FACSAria III cell sorter (BD) with a cell purity typically around 96\%. The gating strategy is depicted in Supplementary Fig. S2b.

\section{RNA-sequencing analysis of primary lung epithelial cells}

533 Total RNA was extracted from sort-purified lung epithelial cells from wildtype, AhR ${ }^{-/}$and $534 \mathrm{CYP}_{\mathrm{BB}} 1^{-/}$mice using a RNeasy Micro Kit (Qiagen) and eluted in nuclease-free water. RNA 535 was desiccated to $3 \mu \mathrm{l}$ and denatured for 3 minutes at $72{ }^{\circ} \mathrm{C}$ in the presence of $2.4 \mathrm{mM}$ dNTP 
536 (Invitrogen Carlsbad, USA), $240 \mathrm{nM}$ dT-primer* (Metabion, Planegg, Germany) and $4 \mathrm{U}$ 537 RNase Inhibitor (New England Biolabs, Frankfurt, Germany). Reverse transcription and addition of the template switch oligo was performed at $42{ }^{\circ} \mathrm{C}$ for 90 min after filling up to $10 \mu 1$ with RT buffer mix for a final concentration of 1x superscript II buffer (Invitrogen), $1 \mathrm{M}$ betaine

540 (Themo Scientific), $5 \mathrm{mM}$ DTT (Invitrogen), $6 \mathrm{mM} \mathrm{MgCl} 2$ (Ambion), $1 \mu \mathrm{M}$ TSO-primer* (Metabion), $9 \mathrm{U}$ RNase Inhibitor (NEB) and $90 \mathrm{U}$ Superscript II (Invitrogen). The reverse transcriptase was inactivated at $70{ }^{\circ} \mathrm{C}$ for 15 min and single stranded cDNA was subsequently amplified using Kapa HiFi HotStart Readymix (Roche) at a 1x concentration together with 250 nM UP-primer* (Metabion) under following cycling conditions: initial denaturation at 98 ${ }^{\circ} \mathrm{C}$ for $3 \mathrm{~min}, 10$ cycles $\left[98^{\circ} \mathrm{C} 20 \mathrm{sec}, 67^{\circ} \mathrm{C} 15 \mathrm{sec}, 72{ }^{\circ} \mathrm{C} 6 \mathrm{~min}\right.$ ] and final elongation at $72{ }^{\circ} \mathrm{C}$ for 5 min. The amplified cDNA was purified using 1x volume of Sera-Mag SpeedBeads (GE Healthcare, South Logan, USA) resuspended in a buffer consisting of $10 \mathrm{mM}$ Tris (Applichem, Darmstadt, Germany), 20 mM EDTA (AppliChem), 18.5 \% (w/v) PEG 8000 (Sigma Aldrich) and $2 \mathrm{M}$ sodium chloride solution (Invitrogen). The cDNA quality and concentration was determined with the Fragment Analyzer (Agilent). For library preparation, $1.5 \mathrm{ng}$ cDNA was tagmented using $0.5 \mu 1$ TruePrep Tagment Enzyme V50 and 1x TruePrep Tagment Buffer L (TruePrep DNA Library Prep Kit V2 for Illumina, Vazyme), followed by an incubation step at $55^{\circ} \mathrm{C}$ for $10 \mathrm{~min}$. Next, Illumina indices were added during PCR $\left(72^{\circ} \mathrm{C} 3 \mathrm{~min}, 98^{\circ} \mathrm{C} 30 \mathrm{sec}\right.$, 12 cycles $\left[98^{\circ} \mathrm{C} 10 \mathrm{sec}, 63{ }^{\circ} \mathrm{C} 20 \mathrm{sec}, 72{ }^{\circ} \mathrm{C} 1 \mathrm{~min}\right.$ ], $72{ }^{\circ} \mathrm{C} 5 \mathrm{~min}$ ) with $1 \mathrm{x}$ concentrated KAPA Hifi HotStart Ready Mix and $300 \mathrm{nM}$ dual indexing primers. After PCR, libraries were purified twice with 1x volume Sera-Mag SpeedBeads (GE Healthcare) and quantified with the Fragment Analyzer (Agilent Technologies), followed by Illumina sequencing on a Nextseq500 with a sample sequencing depth of 30 mio reads on average. any base beside thymidine; TSO-primer: AAGCAGTGGTATCAACGCAGAGTACATrGrGrG, where G stands for riboguanosine;

\section{UP-primer: AAGCAGTGGTATCAACGCAGAGT}

Sequencing reads were pre-processed with bbduk (https://sourceforge.net/projects/bbmap/48 $)$ to remove adapters still present in the raw reads and for quality trimming. Pre-processed reads were mapped to the mouse genome mm10 using GSNAP version 2020-03-1249. RNA sequencing quality was accessed using RNA-SeQC version 2.3.5 $5^{50}$. Read counts were obtained using featureCounts version 2.0.0 $0^{51}$. Splice site support and gene annotations were made using 
570 the Ensemble mm10 genome release version 99. Gene counts were filtered using the 571 Bioconductor's AnnotationHub package (R package version 2.18.0) to contain only protein 572 coding genes. The protein coding genes were used for a differential expression analysis using 573 the Bioconductor package edge $\mathrm{R}^{52}$. Genes were considered as differentially expressed when

574 FDR corrected $p$-values were $<=0.05$. Differentially expressed genes were used as input on a 575 gene ontology enrichment analysis using the R package topGO (R package version 2.38.1). 576 Only nodes containing at least 10 genes were considered in the analysis, using the classic 577 algorithm with the Fisher's exact test, and the p values were corrected using False Discovery 578 Rate (FDR). Additionally, a Fisher's exact test was used to detect KEGG metabolic maps ${ }^{53}$ 579 that were enriched for differentially expressed genes. This enrichment test was performed in an 580 automated fashion using all available maps, and the resulting $\mathrm{p}$ values were also adjusted using 581 FDR correction. Annotations from maps under "Human Disease" and "Drug Discovery" were 582 ignored for the interpretation of the results, and only "Immune System" was used from heading 583 “Organismal systems". All RNA-seq related calculations were performed using the R 584 environment for statistical computing. The raw data is available at the National Center for 585 Biotechnology Information's Gene Expression Omnibus database and are accessible through 586 GEO Series accession number

587 (https://www.ncbi.nlm.nih.gov/geo/query/acc.cgi?acc=GSE158715).

\section{Statistics}

590 Mouse data is displayed as mean $\pm \mathrm{SEM}$, histological and metabolite analysis as mean $\pm \mathrm{SD}$.

591 Statistical significance was determined by ANOVA with Tukey's multiple comparisons or by 592 Student's unpaired two-tailed t-test with or without Welch's correction. The analysis was 593 performed by GraphPad Prism software (version 7.0 and 8.0). Statistical analysis of RNAseq 594 and microarray datasets was performed using R language for statistical computing. 
597 The authors wish to thank the animal caretakers of the Helmholtz Center Munich and Benjamin

598 Schnautz, Johanna Grosch and Anela Arifovic for excellent technical assistance. This work was

599 supported by grants from the European Research Council (ERC Starting grant project number

600716718 to C.O.) and the Deutsche Forschungsgemeinschaft (grant number OH 282/1-1 within

601 FOR2599 to C.O. and project P07 within SFB1371 to C.O.). R.d.J. was supported by a

602 fellowship from the Humboldt foundation (grant number 1200905 - HFST-P). M.W. was

603 supported by the Christine-Kühne Center (CK-Care). C.H. is supported by a fellowship grant

604 \#2019/14245-1, and by grant \#2013/07914-8 from the São Paulo Research Foundation

605 (FAPESP). The VBCF Metabolomics Facility is supported by the City of Vienna through the

606 Vienna Business Agency.

607

\section{Author contribution}

609 Study design: J.T.B., C.B.S.-W. and C.O. Design and conduction of experiments F.A., R.d.J., 610 M.W., A-M.M., I.F., M.H. and C.O. Data analysis: F.A., R.d.J., M.W., A-M.M. and I.F. 611 Bioinformatic analyses: C.H., U.Z. Supervision: F.A., J.T.B., T.B., J.EvB., C.B.S.-W., C.O. 612 Writing original draft: F.A., R.d.J. and C.O. Review\&Editing: All Authors. Funding 613 Acquisition: C.O.

614

\section{Conflict of interest}

616 The authors declare no conflict of interest related to this publication.

\section{References}

619

1. Stockinger B, Di Meglio P, Gialitakis M, Duarte JH. The aryl hydrocarbon receptor: multitasking in the immune system. Annu Rev Immunol 2014; 32: 403-432.

2. Veldhoen M, Hirota K, Christensen J, O'Garra A, Stockinger B. Natural agonists for aryl hydrocarbon receptor in culture medium are essential for optimal differentiation of Th17 T cells. J Exp Med 2009; 206(1): 43-49.

3. Kiss EA, Vonarbourg C, Kopfmann S, Hobeika E, Finke D, Esser C et al. Natural aryl hydrocarbon receptor ligands control organogenesis of intestinal lymphoid follicles. Science 2011; 334(6062): 1561-1565.

4. Gilles S, Fekete A, Zhang X, Beck I, Blume C, Ring J et al. Pollen metabolome analysis reveals adenosine as a major regulator of dendritic cell-primed $\mathrm{T}(\mathrm{H})$ cell responses. $J$ Allergy Clin Immunol 2011; 127(2): 454-461 e451-459. 
5. Schiering C, Wincent E, Metidji A, Iseppon A, Li Y, Potocnik AJ et al. Feedback control of AHR signalling regulates intestinal immunity. Nature 2017; 542(7640): 242 245.

6. Di Meglio P, Duarte JH, Ahlfors H, Owens ND, Li Y, Villanova F et al. Activation of the aryl hydrocarbon receptor dampens the severity of inflammatory skin conditions. Immunity 2014; 40(6): 989-1001.

7. Schulz VJ, Smit JJ, Willemsen KJ, Fiechter D, Hassing I, Bleumink R et al. Activation of the aryl hydrocarbon receptor suppresses sensitization in a mouse peanut allergy model. Toxicol Sci 2011; 123(2): 491-500.

8. van den Bogaard EH, Bergboer JG, Vonk-Bergers M, van Vlijmen-Willems IM, Hato $\mathrm{SV}$, van der Valk PG et al. Coal tar induces AHR-dependent skin barrier repair in atopic dermatitis. J Clin Invest 2013; 123(2): 917-927.

9. Xu T, Zhou Y, Qiu L, Do DC, Zhao Y, Cui Z et al. Aryl Hydrocarbon Receptor Protects Lungs from Cockroach Allergen-Induced Inflammation by Modulating Mesenchymal Stem Cells. J Immunol 2015; 195(12): 5539-5550.

10. Chang YD, Li CH, Tsai CH, Cheng YW, Kang JJ, Lee CC. Aryl hydrocarbon receptor deficiency enhanced airway inflammation and remodeling in a murine chronic asthma model. FASEB J 2020; 34(11): 15300-15313.

11. Negishi T, Kato Y, Ooneda O, Mimura J, Takada T, Mochizuki H et al. Effects of aryl hydrocarbon receptor signaling on the modulation of TH1/TH2 balance. $J$ Immunol 2005; 175(11): 7348-7356.

12. Kawabata Y, Aoki Y, Matsui T, Yamamoto K, Sato H, Onoue S et al. Stable dry powder inhaler formulation of tranilast attenuated antigen-evoked airway inflammation in rats. Eur J Pharm Biopharm 2011; 77(1): 178-181.

13. Hu W, Zhao J, Pei G. Activation of aryl hydrocarbon receptor (ahr) by tranilast, an antiallergy drug, promotes miR-302 expression and cell reprogramming. J Biol Chem 2013; 288(32): 22972-22984.

14. Darakhshan S, Pour AB. Tranilast: a review of its therapeutic applications. Pharmacol Res 2015; 91: 15-28.

15. Li S, Bostick JW, Ye J, Qiu J, Zhang B, Urban JF, Jr. et al. Aryl Hydrocarbon Receptor Signaling Cell Intrinsically Inhibits Intestinal Group 2 Innate Lymphoid Cell Function. Immunity 2018; 49(5): 915-928 e915.

16. Nguyen NT, Kimura A, Nakahama T, Chinen I, Masuda K, Nohara K et al. Aryl hydrocarbon receptor negatively regulates dendritic cell immunogenicity via a kynurenine-dependent mechanism. Proc Natl Acad Sci U S A 2010; 107(46): 1996119966.

17. Cui Z, Feng Y, Li D, Li T, Gao P, Xu T. Activation of aryl hydrocarbon receptor (AhR) in mesenchymal stem cells modulates macrophage polarization in asthma. $J$ Immunotoxicol 2020; 17(1): 21-30. 
18. Piper CJM, Rosser EC, Oleinika K, Nistala K, Krausgruber T, Rendeiro AF et al. Aryl Hydrocarbon Receptor Contributes to the Transcriptional Program of IL-10-Producing Regulatory B Cells. Cell Rep 2019; 29(7): 1878-1892 e1877.

19. Vaidyanathan B, Chaudhry A, Yewdell WT, Angeletti D, Yen WF, Wheatley AK et al. The aryl hydrocarbon receptor controls cell-fate decisions in B cells. J Exp Med 2017; 214(1): 197-208.

20. Polonikov AV, Ivanov VP, Solodilova MA. Genetic variation of genes for xenobioticmetabolizing enzymes and risk of bronchial asthma: the importance of gene-gene and gene-environment interactions for disease susceptibility. J Hum Genet 2009; 54(8): 440-449.

21. DiNatale BC, Murray IA, Schroeder JC, Flaveny CA, Lahoti TS, Laurenzana EM et al. Kynurenic acid is a potent endogenous aryl hydrocarbon receptor ligand that synergistically induces interleukin-6 in the presence of inflammatory signaling. Toxicol Sci 2010; 115(1): 89-97.

22. Hubbard TD, Murray IA, Perdew GH. Indole and Tryptophan Metabolism: Endogenous and Dietary Routes to Ah Receptor Activation. Drug Metab Dispos 2015; 43(10): 15221535.

23. Boyd MR. Evidence for the Clara cell as a site of cytochrome P450-dependent mixedfunction oxidase activity in lung. Nature 1977; 269(5630): 713-715.

24. Chang H, Chang LW, Cheng YH, Tsai WT, Tsai MX, Lin P. Preferential induction of CYP1A1 and CYP1B1 in CCSP-positive cells. Toxicol Sci 2006; 89(1): 205-213.

25. Kerzee JK, Ramos KS. Constitutive and inducible expression of Cypla1 and Cyp1b1 in vascular smooth muscle cells: role of the Ahr bHLH/PAS transcription factor. Circ Res 2001; 89(7): 573-582.

26. Smerdova L, Smerdova J, Kabatkova M, Kohoutek J, Blazek D, Machala M et al. Upregulation of CYP1B1 expression by inflammatory cytokines is mediated by the $\mathrm{p} 38$ MAP kinase signal transduction pathway. Carcinogenesis 2014; 35(11): 2534-2543.

27. Metidji A, Omenetti S, Crotta S, Li Y, Nye E, Ross E et al. The Environmental Sensor AHR Protects from Inflammatory Damage by Maintaining Intestinal Stem Cell Homeostasis and Barrier Integrity. Immunity 2018; 49(2): 353-362 e355.

28. Nakao A. Clockwork allergy: How the circadian clock underpins allergic reactions. $J$ Allergy Clin Immunol 2018; 142(4): 1021-1031.

29. Pariollaud M, Gibbs JE, Hopwood TW, Brown S, Begley N, Vonslow R et al. Circadian clock component REV-ERBalpha controls homeostatic regulation of pulmonary inflammation. J Clin Invest 2018; 128(6): 2281-2296.

30. Gibbs J, Ince L, Matthews L, Mei J, Bell T, Yang N et al. An epithelial circadian clock controls pulmonary inflammation and glucocorticoid action. Nat Med 2014; 20(8): 919926. 
31. Halwani R, Al-Muhsen S, Al-Jahdali H, Hamid Q. Role of transforming growth factorbeta in airway remodeling in asthma. Am J Respir Cell Mol Biol 2011; 44(2): 127-133.

32. Frischmeyer-Guerrerio PA, Guerrerio AL, Oswald G, Chichester K, Myers L, Halushka MK et al. TGFbeta receptor mutations impose a strong predisposition for human allergic disease. Sci Transl Med 2013; 5(195): 195ra194.

33. Buters JT, Sakai S, Richter T, Pineau T, Alexander DL, Savas U et al. Cytochrome P450 CYP1B1 determines susceptibility to 7, 12-dimethylbenz[a]anthracene-induced lymphomas. Proc Natl Acad Sci U S A 1999; 96(5): 1977-1982.

34. Bansal S, Leu AN, Gonzalez FJ, Guengerich FP, Chowdhury AR, Anandatheerthavarada HK et al. Mitochondrial targeting of cytochrome P450 (CYP) 1B1 and its role in polycyclic aromatic hydrocarbon-induced mitochondrial dysfunction. J Biol Chem 2014; 289(14): 9936-9951.

35. Bessede A, Gargaro M, Pallotta MT, Matino D, Servillo G, Brunacci C et al. Aryl hydrocarbon receptor control of a disease tolerance defence pathway. Nature 2014; 511(7508): 184-190.

36. Sadik A, Somarribas Patterson LF, Ozturk S, Mohapatra SR, Panitz V, Secker PF et al. IL4I1 Is a Metabolic Immune Checkpoint that Activates the AHR and Promotes Tumor Progression. Cell 2020; 182(5): 1252-1270 e1234.

37. Tanaka G, Kanaji S, Hirano A, Arima K, Shinagawa A, Goda C et al. Induction and activation of the aryl hydrocarbon receptor by IL-4 in B cells. Int Immunol 2005; 17(6): 797-805.

38. Zissler UM, Chaker AM, Effner R, Ulrich M, Guerth F, Piontek G et al. Interleukin-4 and interferon-gamma orchestrate an epithelial polarization in the airways. Mucosal Immunol 2016; 9(4): 917-926.

39. Mezrich JD, Fechner JH, Zhang X, Johnson BP, Burlingham WJ, Bradfield CA. An interaction between kynurenine and the aryl hydrocarbon receptor can generate regulatory T cells. J Immunol 2010; 185(6): 3190-3198.

40. Kyoreva M, Li Y, Hoosenally M, Hardman-Smart J, Morrison K, Tosi I et al. CYP1A1 Enzymatic Activity Influences Skin Inflammation Via Regulation of the AHR Pathway. J Invest Dermatol 2020.

41. Schmidt JV, Su GH, Reddy JK, Simon MC, Bradfield CA. Characterization of a murine Ahr null allele: involvement of the Ah receptor in hepatic growth and development. Proc Natl Acad Sci U S A 1996; 93(13): 6731-6736.

42. Dalton TP, Dieter MZ, Matlib RS, Childs NL, Shertzer HG, Genter MB et al. Targeted knockout of Cyplal gene does not alter hepatic constitutive expression of other genes in the mouse [Ah] battery. Biochem Biophys Res Commun 2000; 267(1): 184-189. 
43. Pineau T, Fernandez-Salguero P, Lee SS, McPhail T, Ward JM, Gonzalez FJ. Neonatal lethality associated with respiratory distress in mice lacking cytochrome P450 1A2. Proc Natl Acad Sci U S A 1995; 92(11): 5134-5138.

44. Wimmer M, Alessandrini F, Gilles S, Frank U, Oeder S, Hauser M et al. Pollen-derived adenosine is a necessary cofactor for ragweed allergy. Allergy 2015; 70(8): 944-954.

45. Alessandrini F, Schulz H, Takenaka S, Lentner B, Karg E, Behrendt H et al. Effects of ultrafine carbon particle inhalation on allergic inflammation of the lung. J Allergy Clin Immunol 2006; 117(4): 824-830.

46. Lam HC, Choi AM, Ryter SW. Isolation of mouse respiratory epithelial cells and exposure to experimental cigarette smoke at air liquid interface. J Vis Exp 2011; (48).

47. Sinha M, Lowell CA. Isolation of Highly Pure Primary Mouse Alveolar Epithelial Type II Cells by Flow Cytometric Cell Sorting. Bio Protoc 2016; 6(22).

48. Bushnell B, Rood J, Singer E. BBMerge - Accurate paired shotgun read merging via overlap. PLoS One 2017; 12(10): e0185056.

49. Wu TD, Nacu S. Fast and SNP-tolerant detection of complex variants and splicing in short reads. Bioinformatics 2010; 26(7): 873-881.

50. DeLuca DS, Levin JZ, Sivachenko A, Fennell T, Nazaire MD, Williams C et al. RNASeQC: RNA-seq metrics for quality control and process optimization. Bioinformatics 2012; 28(11): 1530-1532.

51. Liao Y, Smyth GK, Shi W. featureCounts: an efficient general purpose program for assigning sequence reads to genomic features. Bioinformatics 2014; 30(7): 923-930.

52. Robinson MD, McCarthy DJ, Smyth GK. edgeR: a Bioconductor package for differential expression analysis of digital gene expression data. Bioinformatics 2010; 26(1): 139-140.

53. Kanehisa M, Goto S. KEGG: kyoto encyclopedia of genes and genomes. Nucleic Acids Res 2000; 28(1): 27-30. 
Figure 1. AhR and CYP1B1 deficiency aggravates pollen-induced allergic airway

\section{inflammation}

828 (A) Experimental setup. Mice of indicated genotypes were exposed for five weeks to ragweed extract (RWE). Wildtype mice exposed to PBS served as negative controls (PBS). (B) Total

830 IgE (left) at day 0 and endpoint and Amb a 1-specific IgG1 (right), respectively. Mean \pm SEM 831 Total IgE (PBS n=10; WT: $\mathrm{n}=20 ; \mathrm{AhR}^{-/-} \mathrm{n}=17$; CYP1A1 $1^{-/-} \mathrm{n}=5 ; \mathrm{CYP}_{1 \mathrm{~A}} 2^{-/-} \mathrm{n}=5$; CYP1B1 $1^{-/-}$ $832 \mathrm{n}=20$ from up to 3 independent experiments). Amb a 1-specific IgG1 (PBS n=10; WT n=17; $833 \mathrm{AhR}^{-/-} \mathrm{n}=11 ; \mathrm{CYP}_{1 \mathrm{~A}} 1^{-/-} \mathrm{n}=6 ; \mathrm{CYP}_{\mathrm{A}} 2^{-/-} \mathrm{n}=6 ; \mathrm{CYP}^{-1 \mathrm{~B}} 1^{-/-} \mathrm{n}=13$ from up to 3 independent 834 experiments). (C) Total and differential BAL cell counts. Mean \pm SEM (PBS n=9; WT n=21; $835 \mathrm{AhR}^{-/-} \mathrm{n}=15 ; \mathrm{CYP}_{1 \mathrm{~A}} 1^{-/-} \mathrm{n}=6 ; \mathrm{CYP}_{\mathrm{A}} 2^{-/-} \mathrm{n}=6 ; \mathrm{CYP}^{-1 \mathrm{~B}} 1^{-/-} \mathrm{n}=15$ from up to 3 independent 836 experiments). (D) Th2 cell frequency. Mean \pm SEM (PBS $n=6 ;$ WT $n=18 ; A^{-/-} n=12$; CYP1A1 $1^{-/-} \mathrm{n}=4$; CYP1A2 $2^{-/-} \mathrm{n}=4$; CYP1B1 $1^{-/-} \mathrm{n}=14$ from up to 3 independent experiments). (E) CCL11, IL-4, IL-13 and IFN- $\gamma$ expression in whole lung tissue. Mean \pm SEM (PBS n=5; WT $\mathrm{n}=18 ; \mathrm{AhR}^{-/-} \mathrm{n}=16 ; \mathrm{CYP}^{\mathrm{A}} 1^{-/-} \mathrm{n}=6 ; \mathrm{CYP}_{\mathrm{A}} 2^{-/-} \mathrm{n}=6 ; \mathrm{CYP}_{1 B} 1^{-/-} \mathrm{n}=19$ from up to 3 independent experiments). (F) Histological scores (left) and representative lung sections (right) Arrows: inflammatory infiltrate; arrowheads: mucus hypersecretion; scale bar: $100 \mu \mathrm{m}$. Mean $\pm \mathrm{SD}(\mathrm{n}=5$ mice/group). (B-F) One-way ANOVA with Tukey’s multiple comparisons test. ${ }^{*} \mathrm{p}<0.05,{ }^{* *} \mathrm{p}$ $<0.01, * * * \mathrm{p}<0.001, * * * * \mathrm{p}<0.0001$

Figure 2. AhR and CYP1B1 deficiency aggravates HDM-induced allergic airway inflammation

847 (A) Experimental setup. $\mathrm{AhR}^{-/-}$(left) and $\mathrm{CYP}_{\mathrm{BB}} 1^{-/-}$(right) mice were exposed to house dust mite (HDM) extract as indicated. No PBS-treated groups were included because neither WT, $\mathrm{AhR}^{-/-}$nor CYP1B1 $1^{-/}$show signs of airway inflammation after PBS treatment only. (B and $\left.\mathbf{G}\right)$ Total IgE (left) and Der $f$-specific IgG1 (right) at endpoint. Mean \pm SEM. AhR ${ }^{-/}$vs WT: total $\operatorname{IgE}$ n=6/group; Der f sp. IgG1 (WT n=8, $\mathrm{AhR}^{-/-} \mathrm{n}=7$ ); CYP1B1 $1^{-/-}$vs WT: total IgE n=10/group; Der f sp. IgG1 (WT n=8, CYP1B1 ${ }^{-/} \mathrm{n}=7$ ), from two independent experiments. (C and $\left.\mathbf{H}\right)$ Total and differential BAL cell counts. Mean \pm SEM. AhR ${ }^{-/-}$vs WT: $n=10 /$ group from two independent experiments. CYP1B1 $1^{-/}$vs WT: $n=10 /$ group from two independent experiments. (D and I) Th2 cell frequency. Mean \pm SEM. $\mathrm{AhR}^{-/}$vs WT: $\mathrm{n}=5 /$ group; CYP1B1 ${ }^{-/-}$vs WT: $\mathrm{n}=10$ /group from two independent experiments. (E and J) CCL11, IL-4, IL-13, IL-17a expression in whole lung tissue. Mean \pm SEM. $\mathrm{AhR}^{-/}$vs WT: $\mathrm{n}=6-8$ /group. CYP1B1 ${ }^{-/}$vs WT: 
n=6-10/group; pooled from up to two independent experiments. ( $\mathbf{F}$ and $\mathbf{K})$ Histological scores (left) and representative lung sections (right) at endpoint in $\mathrm{AhR}^{-/}$and $\mathrm{CYP} 1 \mathrm{~B} 1^{-/-}$, respectively. \pm SD. $\mathrm{AhR}^{-/-}$vs WT: $\mathrm{n}=8-11$ /group from two independent experiments. CYP1B1 ${ }^{-/-}$vs WT: $\mathrm{n}=4-$ $0.05, * * \mathrm{p}<0.01, * * * \mathrm{p}<0.001$

Figure 3. Non-hematopoietic lung cells express CYP1B1

(A) CYP1B1 expression in $\mathrm{CD}^{-} 5^{-}$relative to $\mathrm{CD} 45^{+}$lung cells from $\mathrm{WT}, \mathrm{AhR}^{-/-}$and $\mathrm{CYP} 1 \mathrm{~B} 1^{-}$ PBS- and HDM-challenged WT murine lungs or (C) human lung sections. Red: CYP1B1, 24h with HDM extract in the presence of the AhR inhibitor CH-223191, IL-4 or a combination of both. Results display top 25 upregulated and top 10 downregulated DEGs identified in the IL-4- and CH-223191-treated group relative to HDM only (center). These DEGs are also shown in NHBEs treated solely with IL-4 (left) or CH-223191 (right), respectively. Mean fold change of 4 independent donors. NHBE, normal human bronchial epithelial cell.

\section{Figure 4. Non-hematopoietic CYP1B1 expression prevents exacerbation of HDM-} induced allergic airway inflammation

(A) Schematic representation of the generation of WT and CYP1B1/- bone marrow chimeras, which were subsequently treated with HDM or PBS (for setup see Fig 2a). (B) Total IgE (left) and Der $f$-specific IgG1 (right) at endpoint. IgE: Mean \pm SEM (WT-BM in CYP1B1 ${ }^{-/-} \mathrm{PBS}$ $\mathrm{n}=9$; WT-BM in CYP1B1 $1^{-/-} \mathrm{HDM}$ n=13; CYP1B1 $1^{-/}-\mathrm{BM}$ in WT PBS n=8; CYP1B1 $1^{-/-B M}$ in WT HDM n =11) from 2 independent experiments. Der $f$-specific IgG1: Mean $\pm \mathrm{SD}, \mathrm{n}=5$ /group.

883 (C) Total and differential BAL cell counts; Mean \pm SEM (WT-BM in CYP1B1 ${ }^{-/-} \mathrm{PBS} n=9$; 884 WT-BM in $\mathrm{CYP}_{1 B 1} 1^{-/-} \mathrm{HDM} \mathrm{n}=13$; $\mathrm{CYP} 1 \mathrm{~B} 1^{-/-}-\mathrm{BM}$ in WT PBS n=8; CYP1B1/--BM in WT 885 HDM n=11) from 2 independent experiments. (D) Th2 cell frequency. Mean \pm SEM (WT-BM in $\mathrm{CYP}_{1 \mathrm{~B}} 1^{-/-} \mathrm{PBS} \mathrm{n}=9$; WT-BM in $\mathrm{CYP}_{\mathrm{B}} 1^{-/-} \mathrm{HDM} \mathrm{n}=13$; CYP1B1/--BM in WT PBS n=8; $\mathrm{CYP}_{\mathrm{B} 1}{ }^{-/-}-\mathrm{BM}$ in WT HDM n=11) from 2 independent experiments. (E) IL-4, IL-13, IFN- $\gamma$, IL-22 and IL-17A protein levels in whole lung tissue. Mean \pm SEM (WT-BM in CYP1B1 ${ }^{-/-}$ PBS n=4; WT-BM in CYP1B1 $1^{-/-}$HDM n=8; CYP1B1 $1^{-/-}$-BM in WT PBS n=4; CYP1B1 $1^{-/-}$BM in WT HDM n=8) from up to 2 independent experiments. (F) Histological scores (left) and 
892

893

894

895

896

897

898

899

900

901

902

903

904

905

906

907

908

909

910

911

912

913

914

915

916

917

918

919

920

921

922

923

924

hypersecretion; scale bar: $100 \mu \mathrm{m}$. Mean $\pm \mathrm{SD}$ (WT-BM in CYP1B1 $1^{-/-} \mathrm{PBS} n=5$; WT-BM in CYP1B1 $1^{-/} \mathrm{HDM} \mathrm{n}^{2}=4$; CYP1B1 ${ }^{-/}-\mathrm{BM}$ in WT PBS n=5; CYP1B1 $1^{-/}-\mathrm{BM}$ in WT HDM n=4). (BF) ANOVA with Tukey's multiple comparisons. BM, bone marrow. ${ }^{*} \mathrm{p}<0.05,{ }^{*} \mathrm{p}<0.01$, $* * * \mathrm{p}<0.001, * * * * \mathrm{p}<0.0001$

\section{Figure 5. AhR regulates gene expression in airway epithelial cells of sensitized mice}

(A) Total DEGs in $\mathrm{AhR}^{-/}$and CYP1B1 ${ }^{-/}$epithelial cells (EC) relatively to WT from untreated or allergic (HDM) mice. (B and $\mathbf{C})$ RNAseq analysis of sort-purified EC $\left(\mathrm{CD} 45^{-} \mathrm{CD} 31^{-} \mathrm{EpCAM}^{+}\right.$live $\left.{ }^{+}\right)$of $\mathrm{AhR}^{-/-}$and $\mathrm{CYP}^{-1 \mathrm{~B}} 1^{-/}$mice. (B) Heatmap of all genes differently expressed in $\mathrm{AhR}^{-/-}$or CYP1B1 $1^{-/-}$versus WT EC at steady state and their expression in HDM-exposed animals. (C) KEGG pathway analysis of DEGs between AhR and WT EC of HDM-exposed animals. Only pathways with at least 5 DEGs are shown.

\section{Figure 6. Functional consequences of CYP1B1 deficiency in airway epithelial cells}

(A) CYP1A1 expression in total lung untreated tissue. Mean \pm SEM (WT n=6, $\mathrm{AhR}^{-/-} \mathrm{n}=4$, CYP1A1 $\left.1^{-/} n=2, C Y P 1 A 2^{-/} n=2, C Y P 1 B 1^{-/-} n=6\right)$. (B) CYP1A1 expression in total lung tissue sensitized to RWE. Mean \pm SEM (WT n=17, $\mathrm{AhR}^{-/-} \mathrm{n}=18, \mathrm{CYP}^{\mathrm{A}} 1^{-/-} \mathrm{n}=6, \mathrm{CYP}_{\mathrm{A}} 2^{-/-} \mathrm{n}=6$, CYP1B1 $1^{-/} \mathrm{n}=20$ ) from up to 3 independent experiments. (C) CYP1A1 expression in total lung tissue sensitized to HDM. Mean \pm SEM (WT $n=10$; CYP1B1 $\left.1^{-/-} n=5\right)$ from up to 2 independent experiments. (D) CYP1A1 expression in CD45 cells isolated from HDM-sensitized of indicated genotypes. Mean $\pm \operatorname{SEM}\left(\mathrm{WT} n=6, \mathrm{AhR}^{-/-} n=3, \mathrm{CYP} 1 \mathrm{~B} 1^{-/-} n=7\right)$. (E) EROD assay in total lung homogenates of indicated genotypes after stimulation with HDM. Mean \pm SEM (n/concentration: WT n=5, CYP1A1 $\left.1^{-/} n=6, \mathrm{CYP}_{\mathrm{A}} 2^{-/-} \mathrm{n}=3, \mathrm{CYP} 1 \mathrm{~B} 1^{-/-} \mathrm{n}=5, \mathrm{AhR}^{-/-} \mathrm{n}=4\right)$. (F) EROD assay in total lung homogenates of indicated genotypes after stimulation with FICZ.

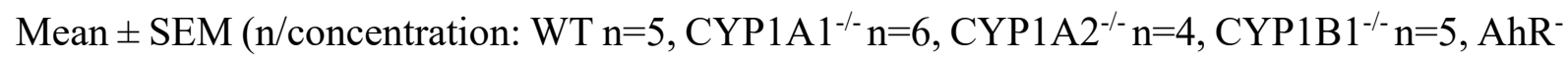
$\left.{ }^{\prime} n=4\right)$. (G) EROD assay of murine MTEC of the indicated genotypes after stimulation with HDM $(10 \mu \mathrm{g} / \mathrm{mL})$ or FICZ $(10 \mathrm{nM})$. Mean \pm SEM; $\mathrm{n}=5 /$ group/treatment. (H) CYP1A1 expression of murine MTEC of the indicated genotypes after stimulation with HDM $(10 \mu \mathrm{g} / \mathrm{mL})$ or FICZ (10nM). Mean \pm SEM; $n=5 /$ group/treatment. (I) Targeted LC-MS/MS measurement of tryptophane, kynurenine and kynurenic acid in lung homogenates of the indicated genotype with or without AAI. Mean $\pm \mathrm{SD}$; $\mathrm{n}=5$ /group/treatment. (A-D) Student's t-test (unpaired, twotailed); (E-I) Student's t-test (unpaired, two-tailed) with Welch's correction. MTEC, mouse tracheobronchial epithelial cells. ${ }^{*} \mathrm{p}<0.05,{ }^{*} \mathrm{p}<0.01,{ }^{* * *} \mathrm{p}<0.001,{ }^{* * * *} \mathrm{p}<0.0001$ 
bioRxiv preprint doi: https://doi.org/10.1101/2021.09.20.461064; this version posted September 23, 2021. The copyright holder for this preprint (which was not certified by peer review) is the author/funder, who has granted bioRxiv a license to display the preprint in perpetuity. It is made available under aCC-BY-NC-ND 4.0 International license.

\section{Figure 1}

A

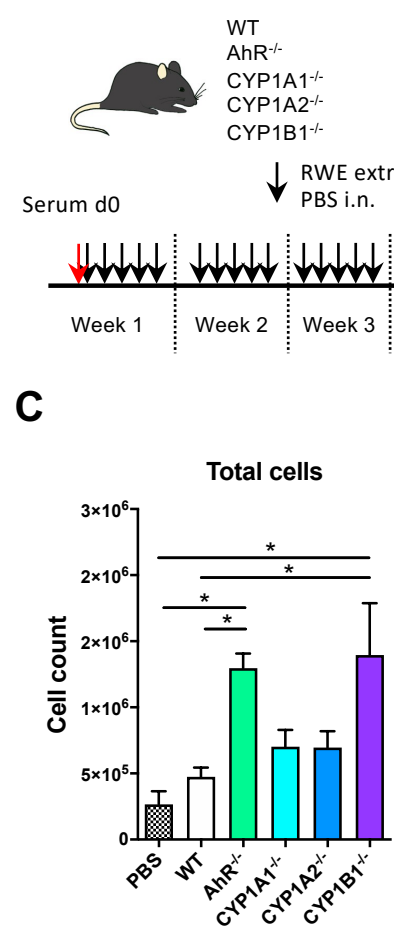

D

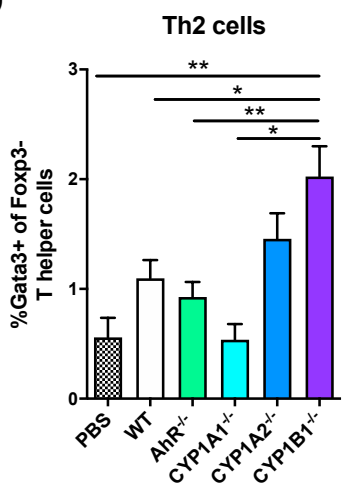

$\mathbf{F}$

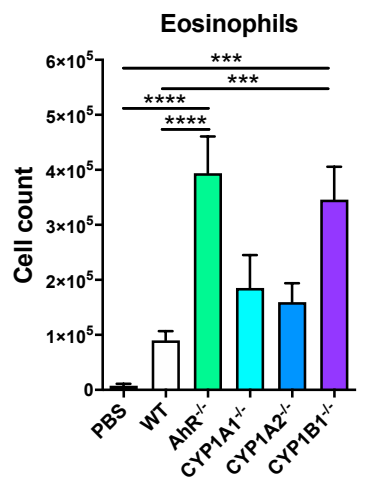

E

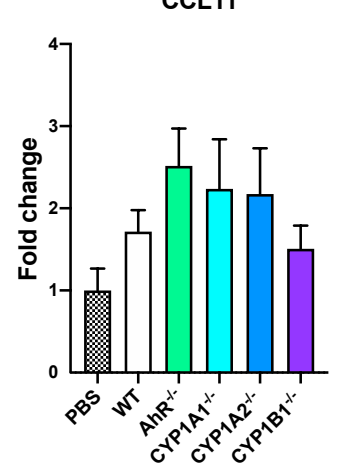

Total IgE

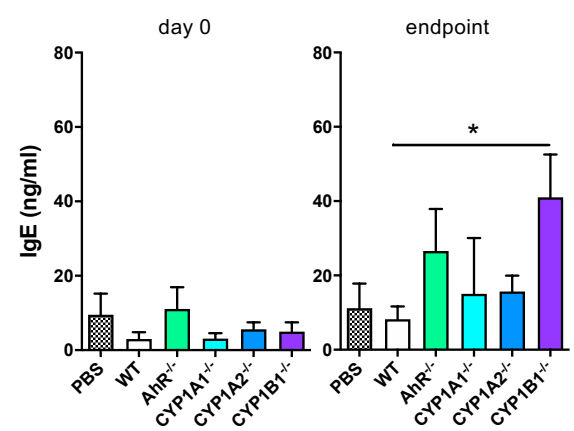

Amb a 1 specific $\lg G 1$
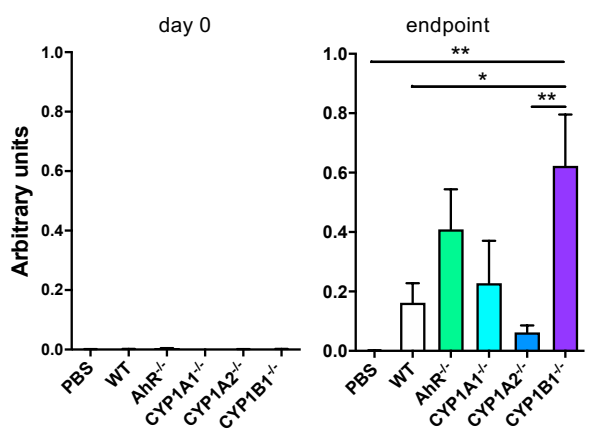

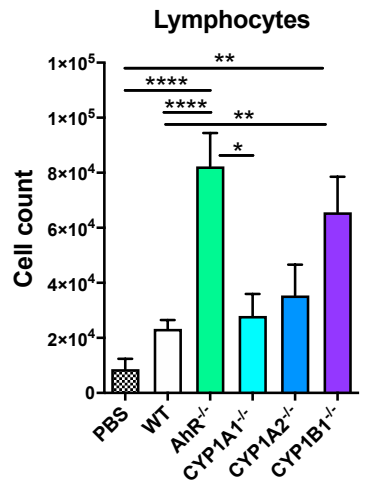

IL-4

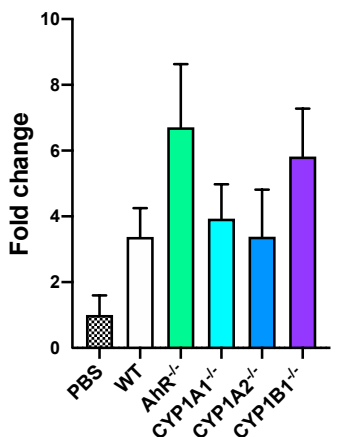

Macrophages

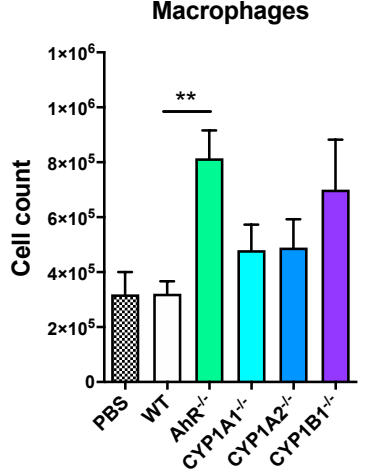

IL-13

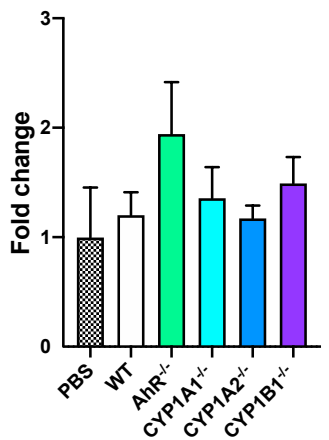

Neutrophils

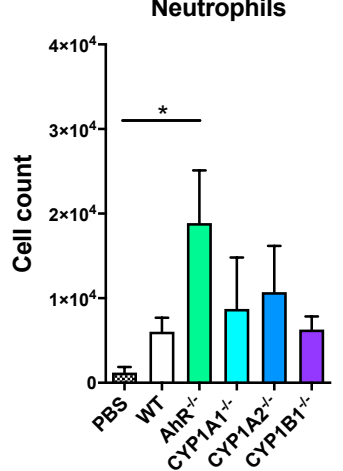

IFN- $\gamma$
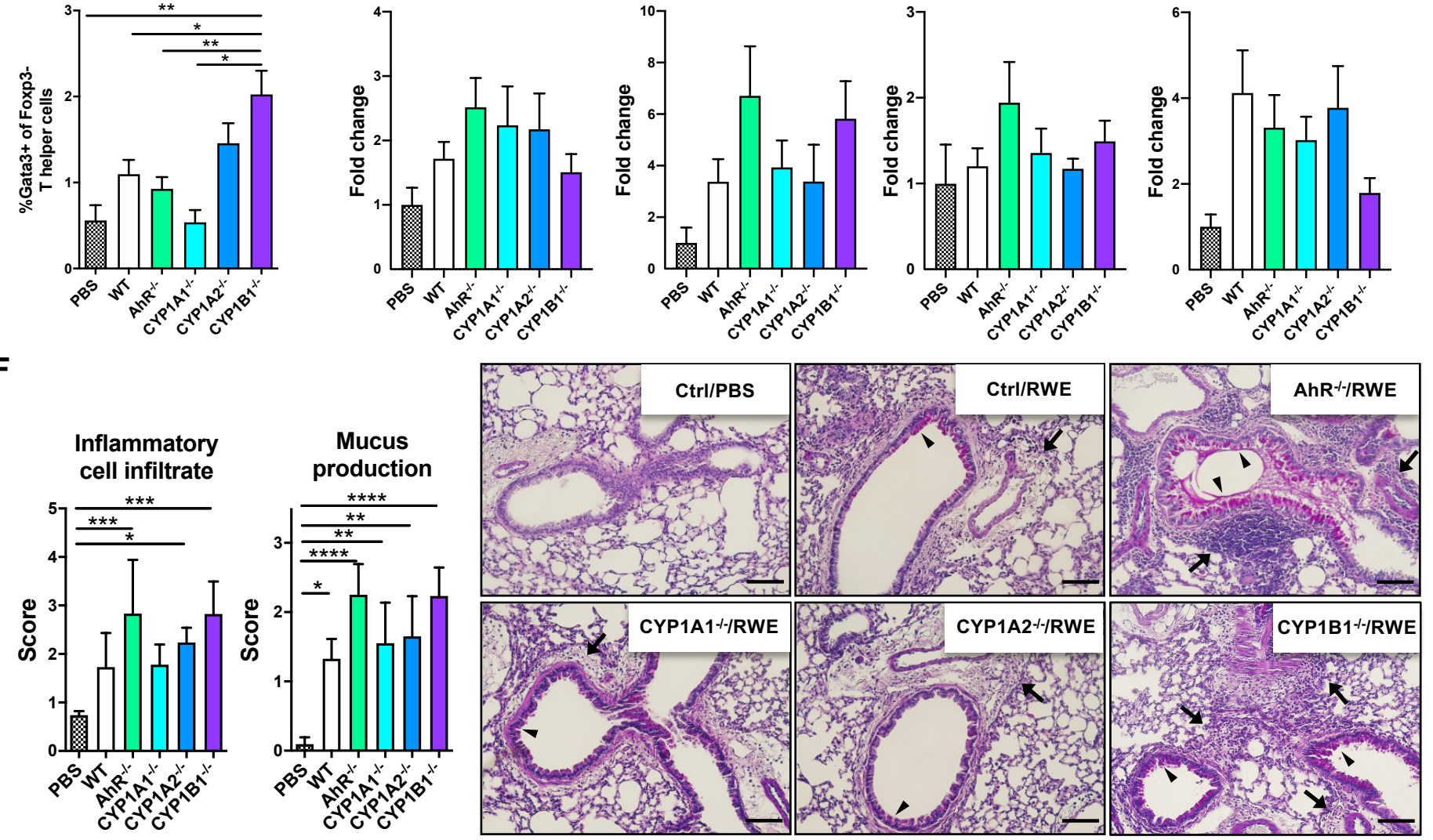
Figure 2

A

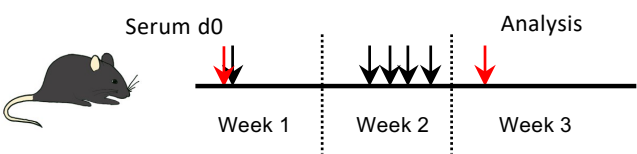

$\mathrm{AhR}^{-/-}$

CYP1B1--

B
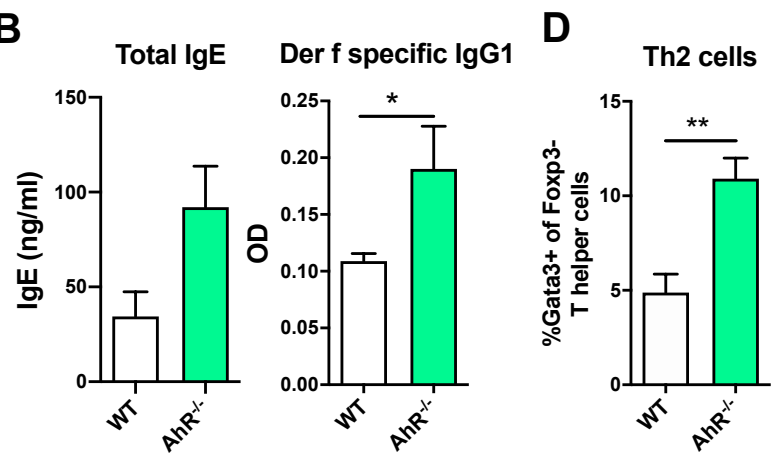

C Total cells

Eosinophils Lymphocytes
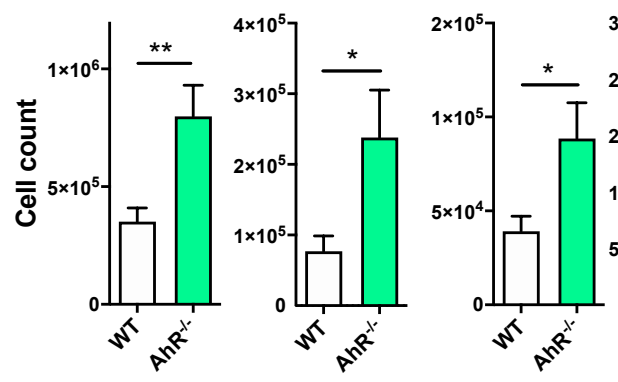

E
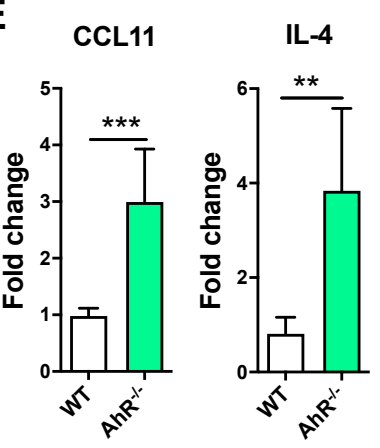

IL-13

IL-17A
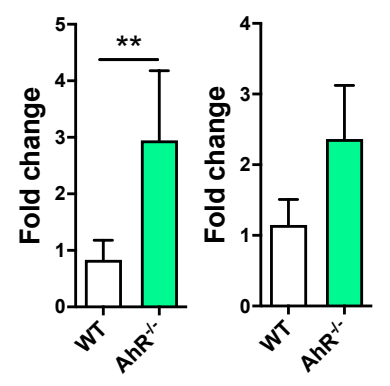

F
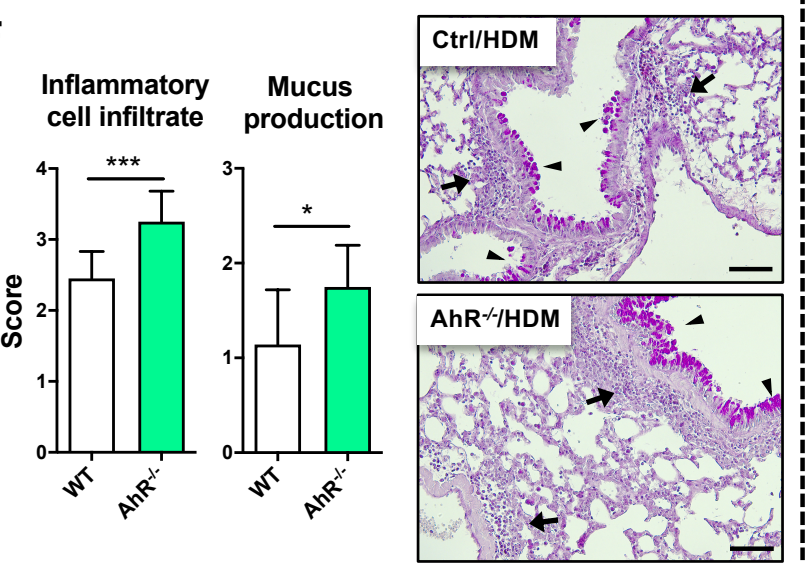

G
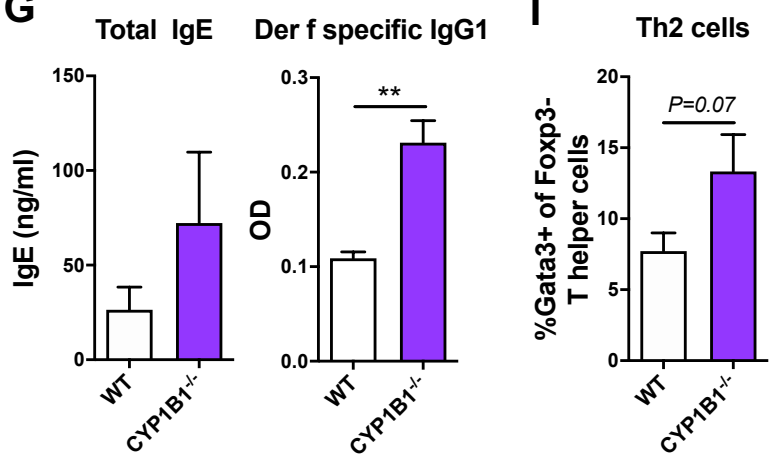

$\mathrm{H}$

Total cells Eosinophils Lymphocytes Macrophages $\underbrace{4 \times 10^{6}}_{2 \times 10^{6}}$

$\mathbf{J}$

$$
\text { CCL-11 IL-4 IL-13 IL-17A }
$$

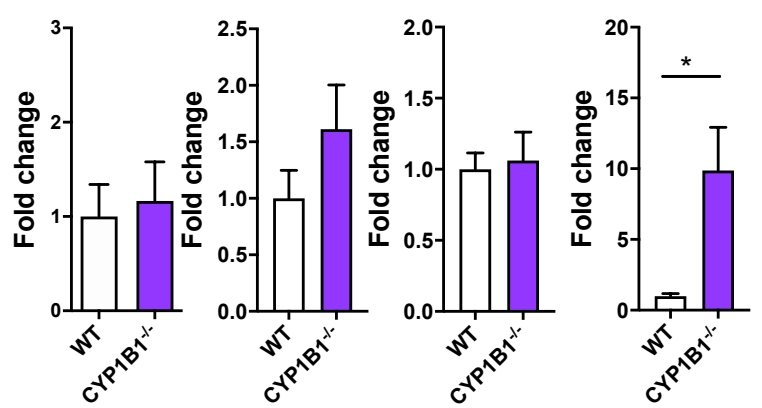

K

Inflammatory Mucus
cell infiltrate

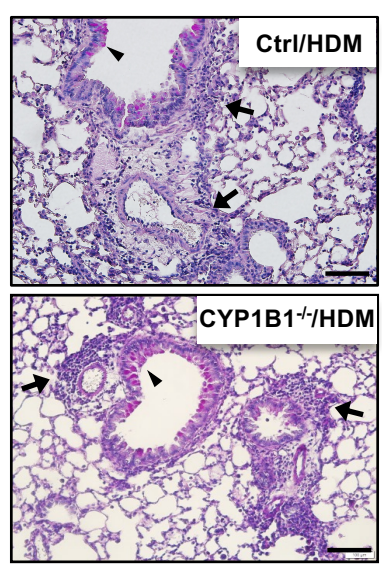


Figure 3

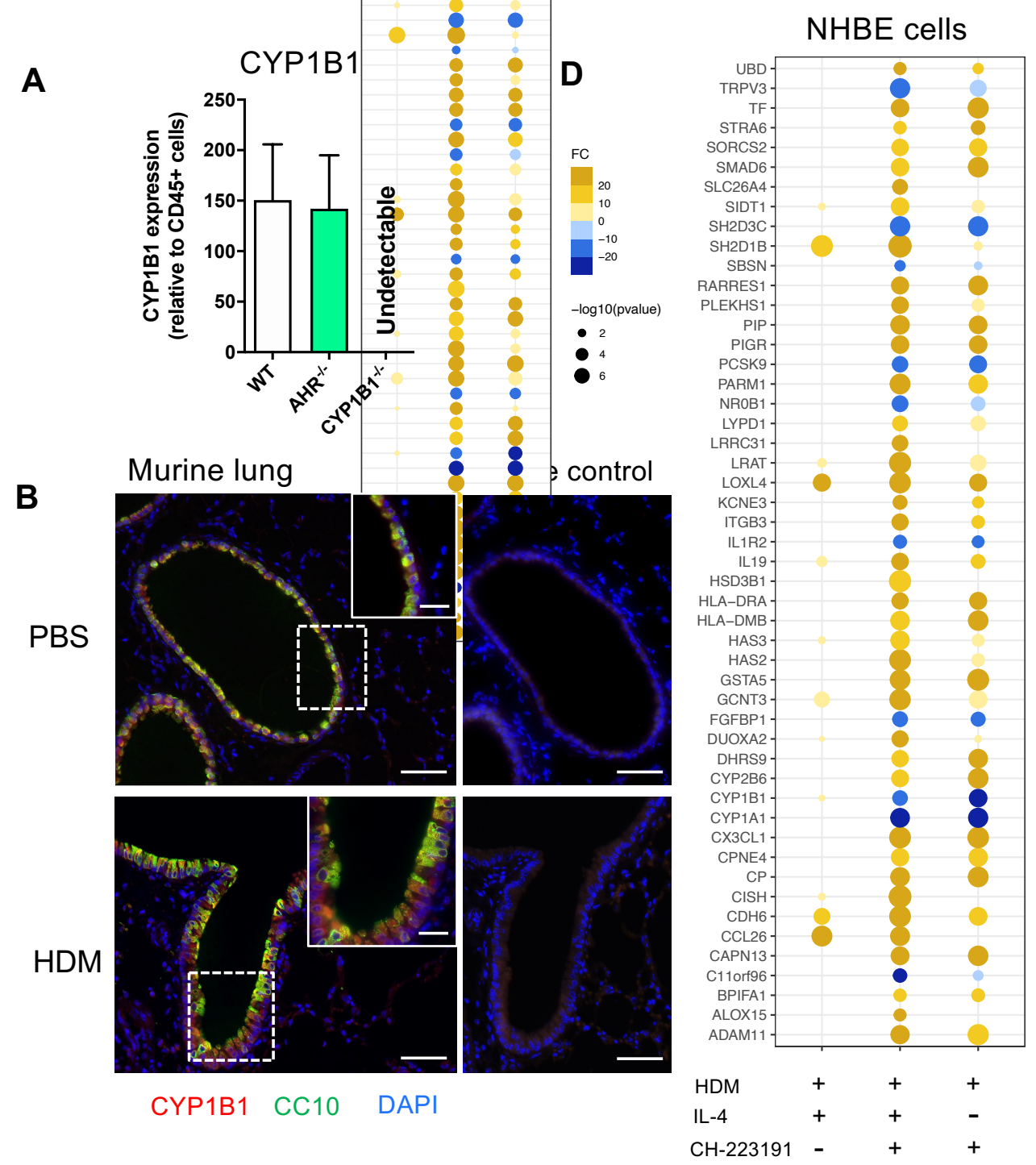

C

Human lung

Isotype control

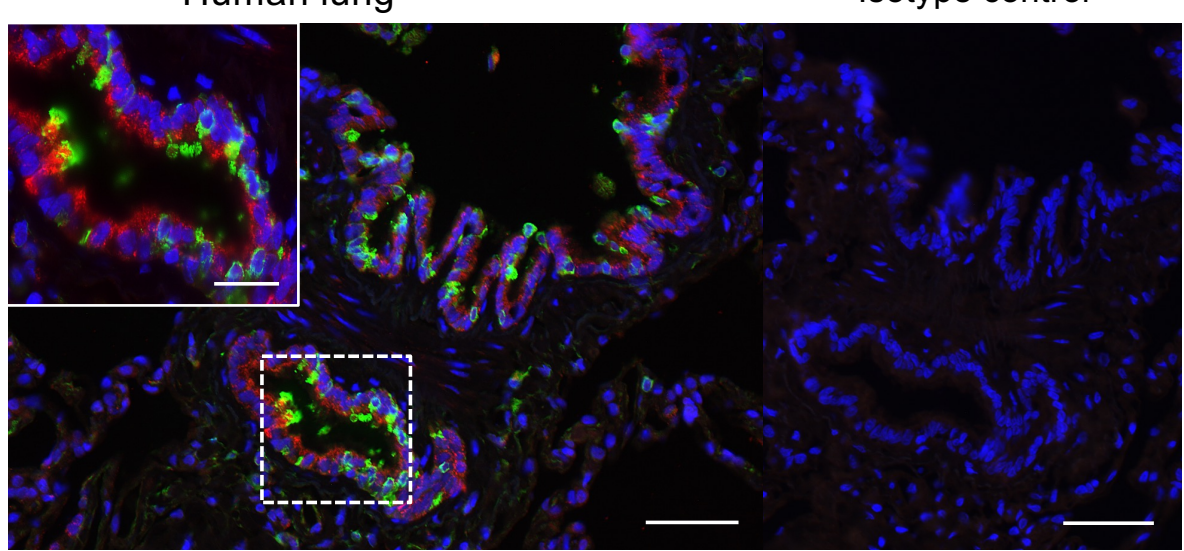

CYP1B1 CC10 DAPI 
Figure 4

A

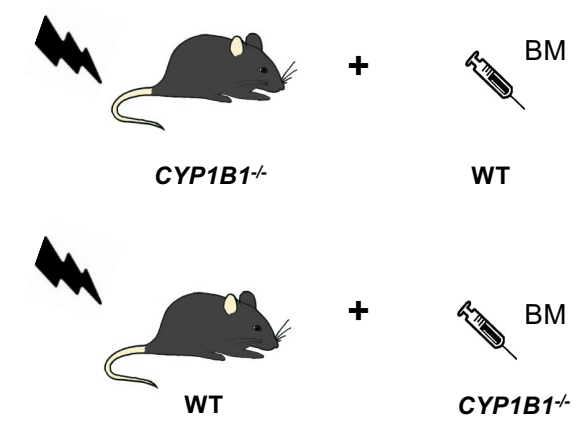

C

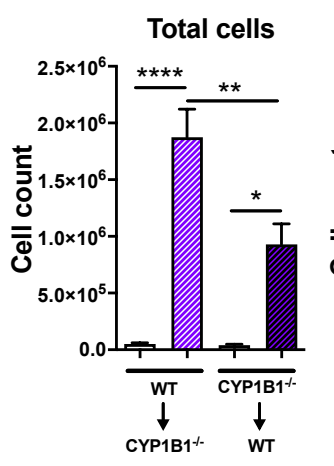

E
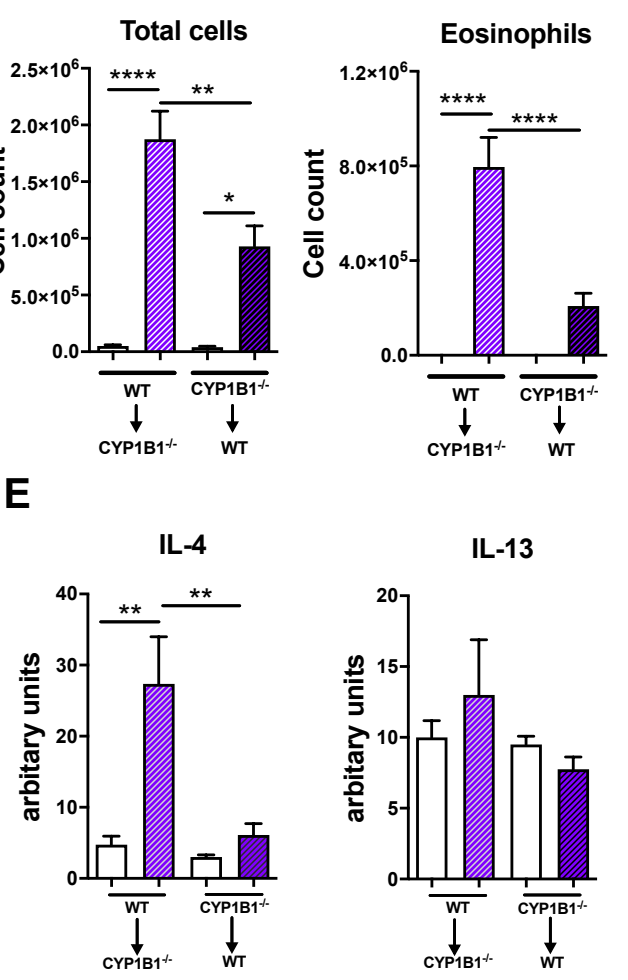

B
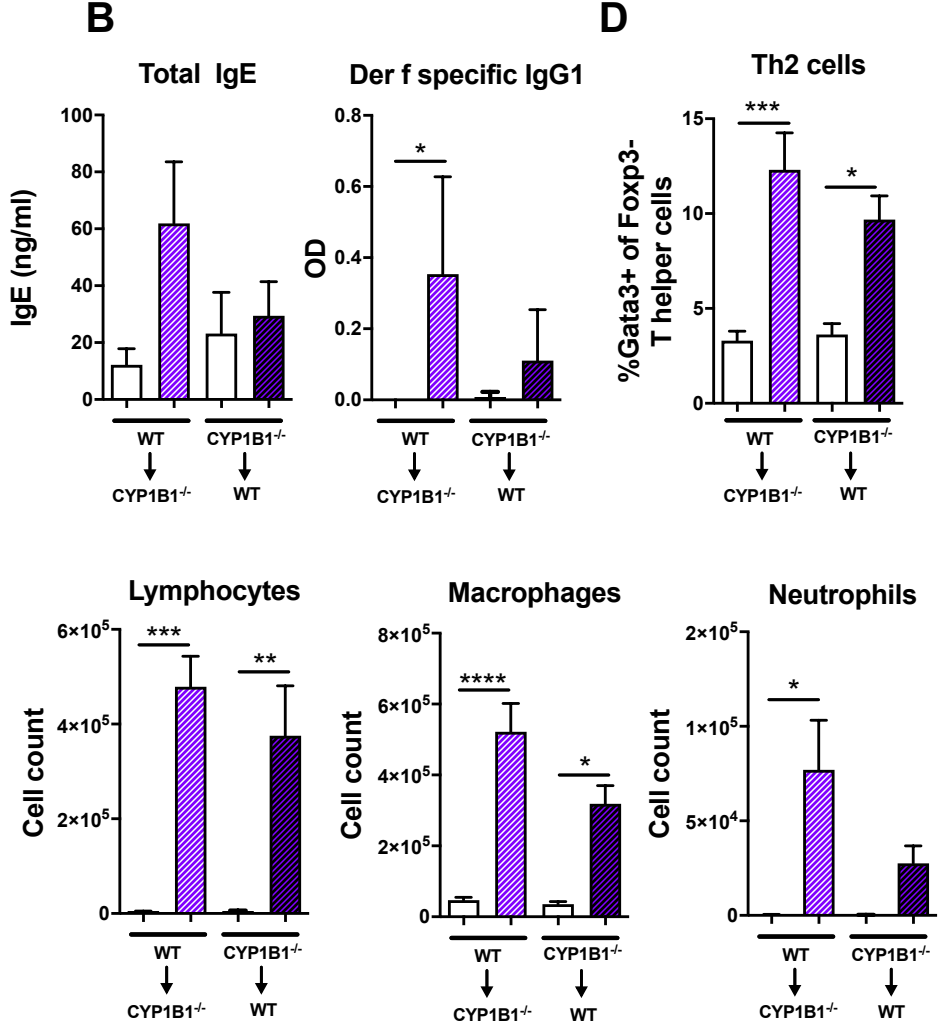

F
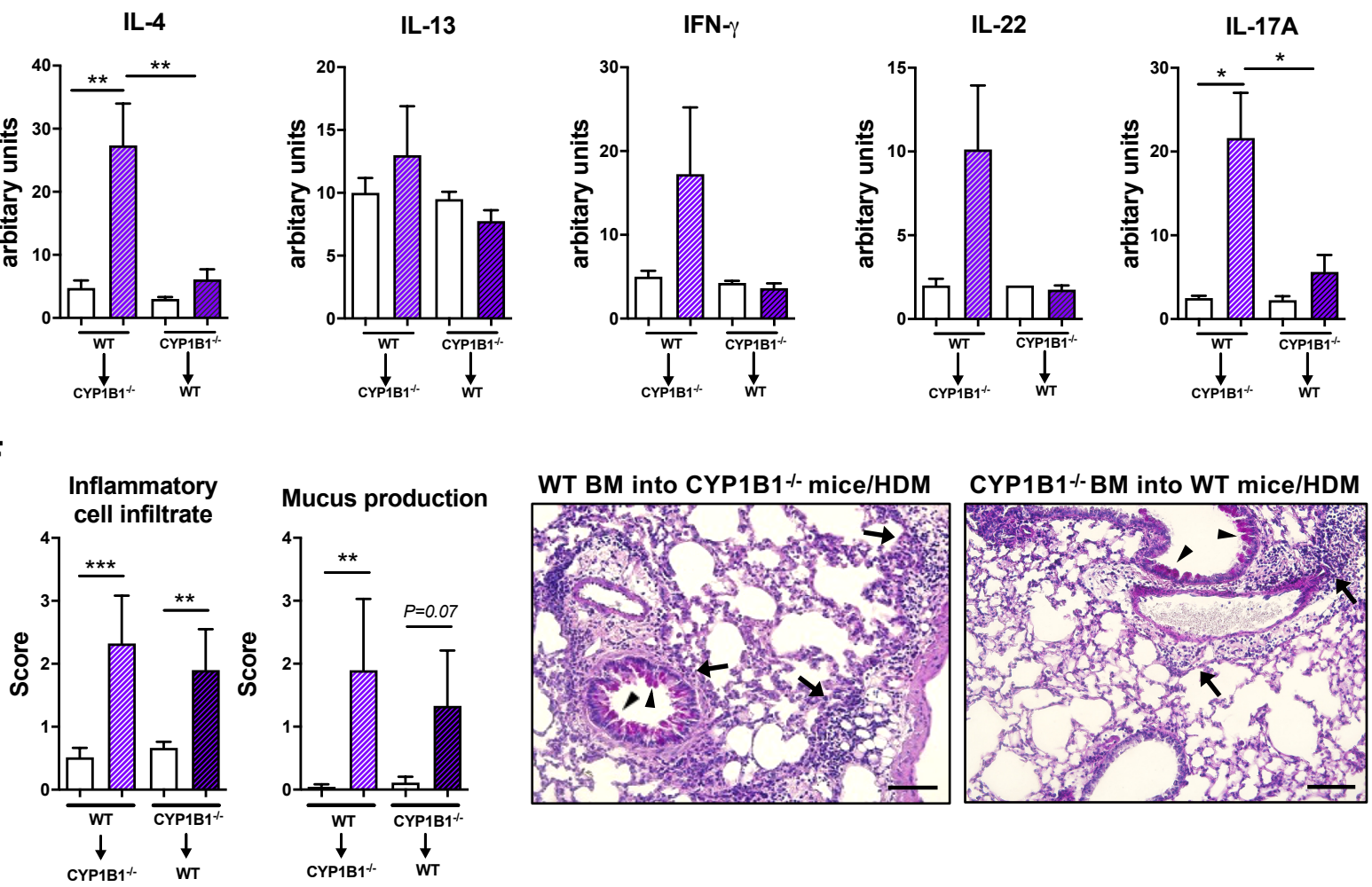


\section{Figure 5}

A

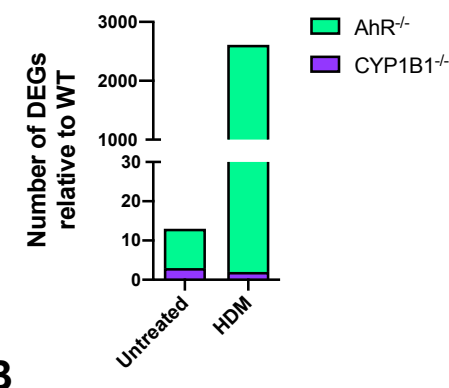

B

DEGs steady state

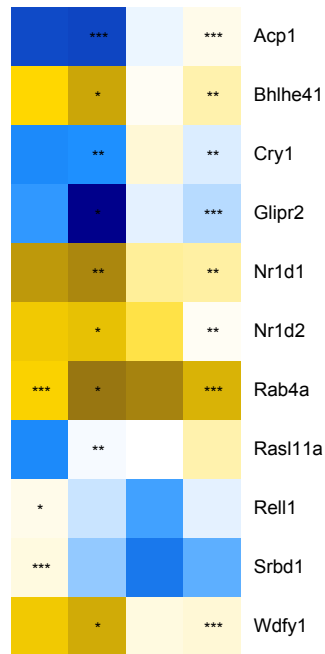

HDM

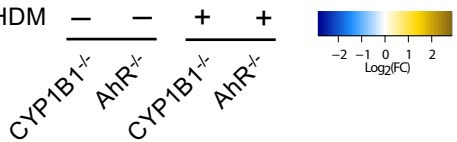

C

KEGG pathway $A h R^{-/-}$vs wildtype CD45-CD31-EpCAM ${ }^{+}$cells

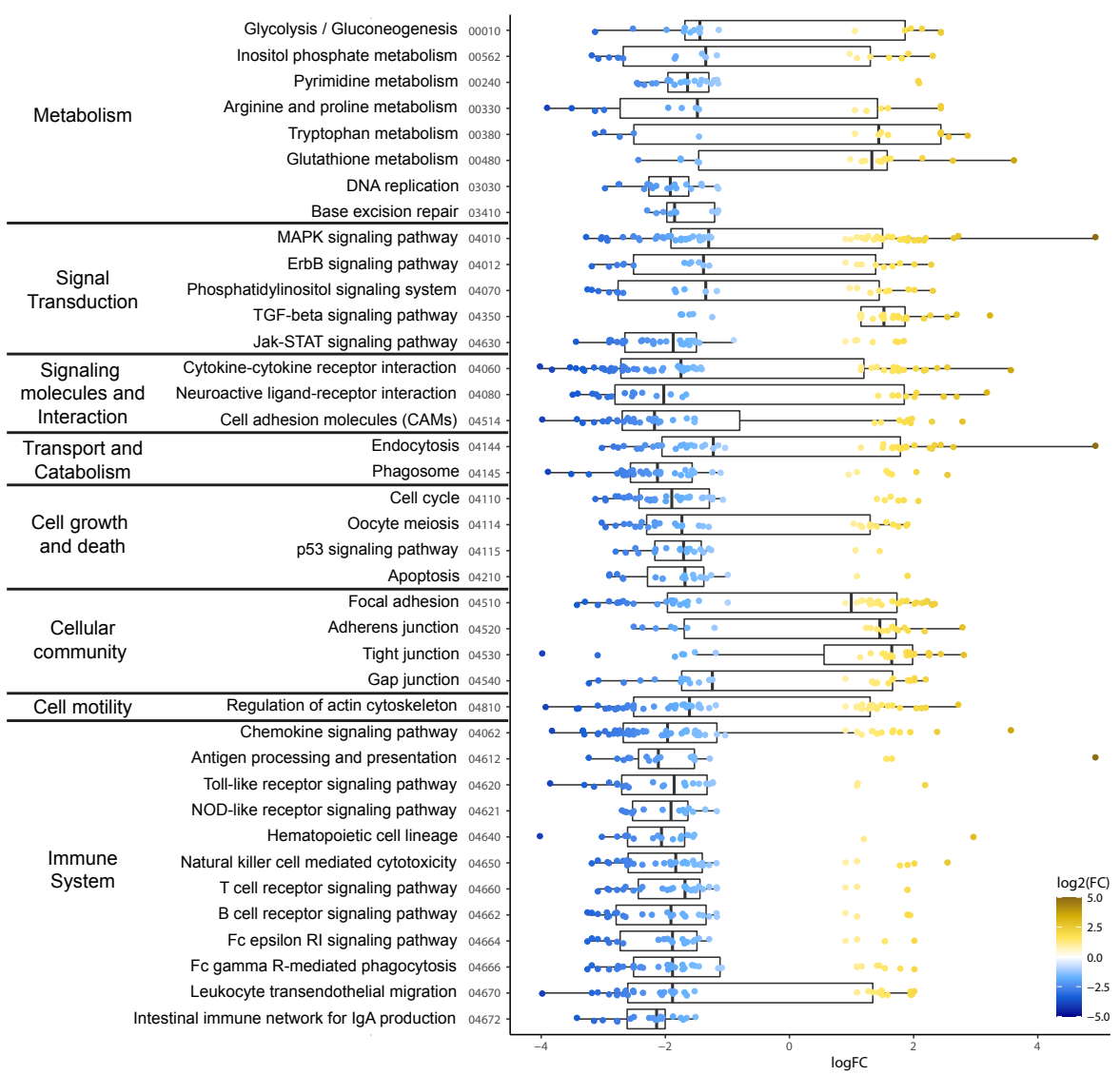


Figure 6

A

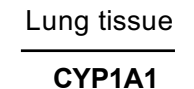

B

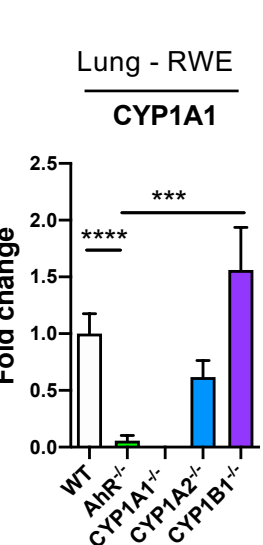

C<smiles>[Mg][Mg][Te]</smiles>

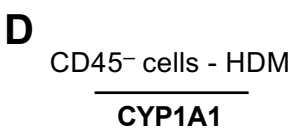

G

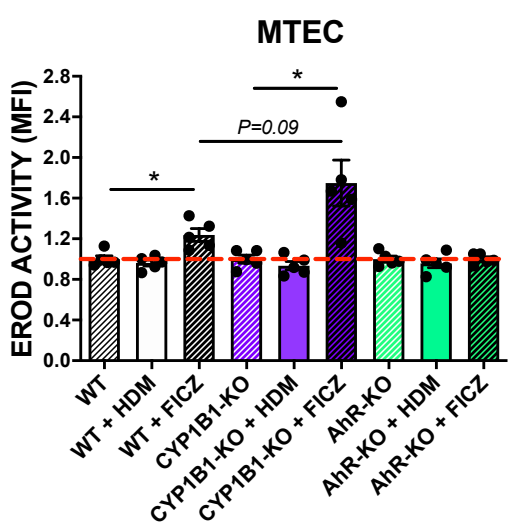

H

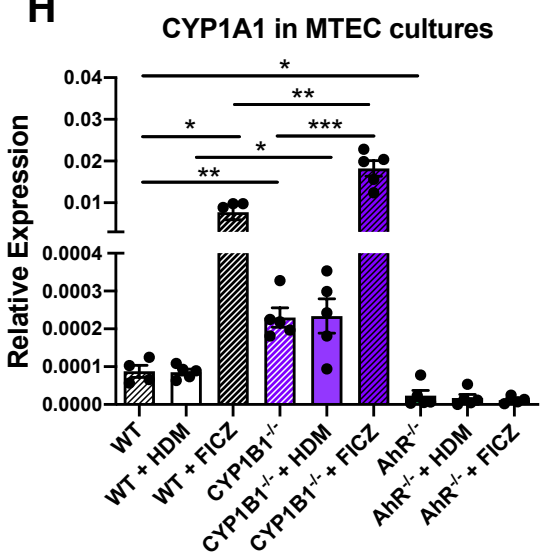

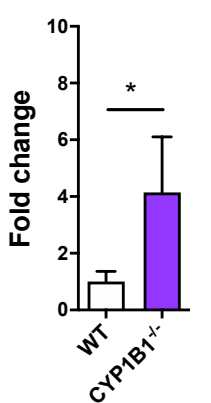

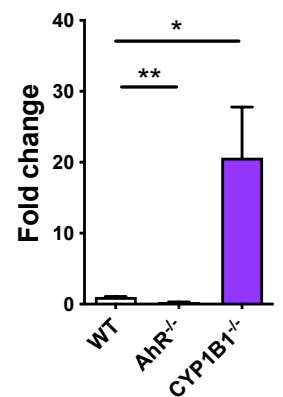

Lung homogenates

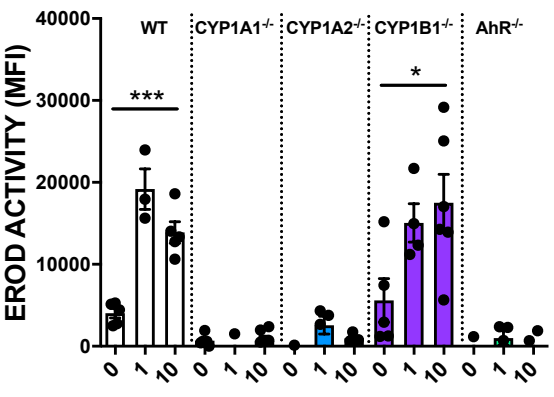

FICZ concentration (nM)
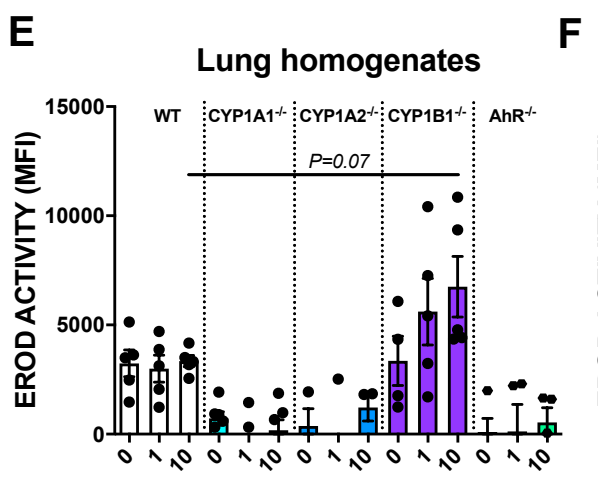

HDM concentration $(\mu \mathrm{g} / \mathrm{ml})$

I
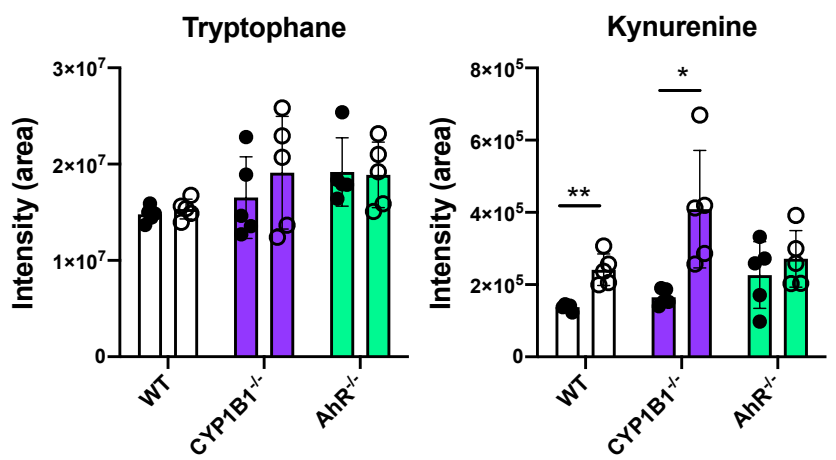

Kynurenic acid

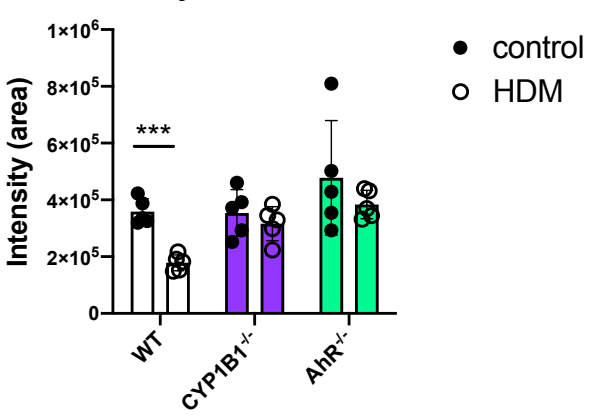

